\title{
Morphogenesis and Territorial Coverage by Isolated Mammalian Retinal Ganglion Cells
}

\author{
P. Read Montague ${ }^{a}$ and Michael J. Friedlander \\ Neurobiology Research Center and Department of Physiology and Biophysics, University of Alabama at Birmingham, \\ Birmingham, Alabama 35294
}

\begin{abstract}
Identified retinal ganglion cells were isolated from postnatal cat retinas and their dendrites were removed by trituration and centrifugation. The denuded cells were placed in a cell culture system and allowed to reexpress dendritic arbors in the absence of afferent input, target tissue, and interactions with neighboring ganglion cells. The retinal ganglion cells were grown above a feeder layer of astrocytes on glass coverslips equipped with paraffin pedestals. The spatial patterns of the reexpressed neurites were quantitatively analyzed using a number of measures, including an estimate of the Hausdorff dimension, $H$, which was used as a scaleindependent metric for how well the neurite patterns filled in a restricted spatial domain. As assessed by the estimation of the Hausdorff dimensions, the neurites from a single cell achieve uniform coverage of a restricted territory independent of the total neurite length or the total number of interbranch-point segments. A comparison with $H$ values of ganglion cells from the intact retina revealed a similar trend. These results suggest that these cultured ganglion cells can express an intrinsic growth strategy for the uniform coverage of a restricted territory. The arbors expressed in the culture system displayed a limited range of diameters and exhibited morphology similar to the $\alpha-, \beta$-, and $\gamma$-ganglion cells of the intact retina in the absence of afferent input or the influences of neighboring cells and target tissue. Time-lapse video data revealed that Individual cultured cells showed extensive dendritic remodeling during their growth; however, after about $3 \mathrm{~d}$ in culture, this remodeling did not appreciably affect the territorial coverage of a cell. In the intact retina, the existence of dendritic sheets that independently and uniformly sample visual space may result from this intrinsic ability to elaborate dendrites that uniformly cover or fill in a restricted territory.
\end{abstract}

The vertebrate retina offers a particularly accessible system to study the development of dendritic structure (Maslim et al., 1986; Ramoa et al., 1987, 1988; Dann et al., 1988) and the

\footnotetext{
Received Sept. 12, 1990; revised Nov. 28, 1990; accepted Dec. 7, 1990.

This work was supported by National Science roundation Grant BNS 8720069 to M.J.F. and by the Sloan Foundation. We gratefully acknowledge the assistance of the University of Alabama at Birmingham Neurobiology Research Center's Cell Imaging Facility, the photographic assistance of Deborah McCarthy, the software development of Mr. Kevin Ramer, and the work-processing skills of Denise Powell and Luisa Beard.

Correspondence should be addressed to Dr. Michael J. Fricdlander, Neurobiology Research Center, University of Alabama at Birmingham, Birmingham, AL 35294.

a Present address: The Neurosciences Institute, 1230 York Avenue, New York, NY 10021.

Copyright (C) 1991 Society for Neuroscience $0270-6474 / 91 / 111440-18 \$ 03.00 / 0$
}

relation between neuronal morphology and function (Dowling, 1987; Rodieck and Brening, 1983). In particular, the retinal ganglion cell ( $R G C)$ represents a CNS neuron for which the study of its dendritic morphology has beautifully complemented knowledge of its physiology. By combining electrophysiological and morphological studies of individual neurons, characteristic anatomical features of RGCs have been correlated with detailed physiological properties of these cells (Peichl and Wassle, 1983, 1984; Rodieck and Brening, 1983; Saito, 1983; Amthor, 1984; Fukuda et al., 1984; Stanford and Sherman, 1984; Stanford, $1987 \mathrm{a}, \mathrm{b})$. For example, the response of an RGC to luminance changes in its receptive field center has been correlated with the level of stratification of the RGC's dendritic processes in the inner plexiform layer of the retina (Nelson et al., 1978). Also, the size of the soma and the dendritic morphology have been correlated with the type of receptive field of the RGC and the kinds of luminance profiles that excite the cell (Nelson et al., 1978; Peichl and Wassle, 1983; Rodieck and Brening, 1983; Saito, 1983; Amthor, 1984; Fukuda et al., 1984; Stanford and Sherman, 1984; Stanford, 1987a,b). Because the relation of structure and function is well established for this cell type, the question of how individual RGCs establish and maintain their characteristic dendritic structure is important for understanding the development of the functional properties of these cells.

Currently, little data are available on how individual RGCs establish their characteristic structure and to what degree this process is intrinsic to these cells. Recent studies (Maslim et al., 1986; Ramoa et al., 1987, 1988; Dann et al., 1988) have analyzed the dendritic morphology of groups of RGCs from the intact retina at various stages of development, including the late prenatal and early postnatal periods. Although this work has significantly increased our understanding of the development and remodeling of dendritic structure, these studies require that developmental properties of individual cells be inferred from collective data obtained from a large number of RGCs, and thus are not able to assess directly the development of an individual neuron. Moreover, it is difficult to separate the intrinsic and extrinsic factors that regulate development with this approach.

Extrinsic environmental factors such as dendritic interactions with neighboring cells clearly play a role in the development of the dendritic morphology of RGCs (Wassle et al., 1981a-c; Perry and Linden, 1982; Perry, 1984; Eysel et al., 1985; Hitchcock, 1989). In contrast, cultured postmitotic neurons derived from other CNS sites such as the hippocampus can generate natural (in situ-like) shapes in a homogeneous cell culture environment (Banker and Cowan, 1977, 1979; Banker and Waxman, 1987), suggesting that intrinsic processes can be sufficient for normal morphological development. In order to address the question 
of the development and maintenance of RGC structure and its dependence on processes intrinsic to the neuron, RGCs from postnatal cats were identified, isolated, and grown in cell culture. These cells were allowed to express dendritic structure in the absence of interactions with afferent input, neighboring retinal cells, and target tissue.

A preliminary account of this work has previously been published (Montague and Friedlander, 1989).

\section{Materials and Methods}

Culture methods. The RGCs in this study were obtained from cats (postnatal age, 1-8 weeks) used in ongoing electrophysiological experiments or from our breeding colony. These neurons were postmitotic (Walsh et al., 1983) and expressed many aspects of adult morphology (Dann et al., 1988; Ramoa et al., 1988). Anesthesia was induced with vaporized Fluothane (0.6-1.3\%, kittens; 3.0\%, adults) in a $1: 1 \mathrm{~N}_{2} \mathrm{O} / \mathrm{O}_{2}$ mixture. After deep anesthesia was achieved, a femoral vein was cannulated with polycthylene tubing. The eyeball was carefully removed. A lethal dose $(120 \mathrm{mg} / \mathrm{kg})$ of Nembutal was then administered into the femoral catheter. The method for the removal and plating of the RGCs is presented in Figure 1.

The feeder layer of astrocytes was initially grown in basal minimum essential medium (BMEM; Gibco) supplemented with $10 \%$ fetal bovine serum (Gibco). At every feeding, the culture vessels were mechanically agitated to detach most of the oligodendrocytes growing on top of the astrocyte monolayer, and the medium was thoroughly aspirated to remove the suspended cells. About $5 \mathrm{~d}$ prior to the plating of the retinal neurons, the astrocytes were transferred to Falcon six-well culture plates, to $35-\mathrm{mm}$ Falcon culture dishes, or to the interiors of cloning cylinders affixed to the bottom of the Falcon $35-\mathrm{mm}$ culture dishes. One day prior to the introduction of the coverslips containing the retinal neurons, the medium was changed to the IIB101-based medium (sec Fig. 1). The presence of the astrocytes was required to support the growth of the RGCs for more than $24 \mathrm{hr}$ (Banker, 1980).

The glass coverslips (16-18 mm diameter) were treated with poly-Llysine (MW, 70,000; Sigma), poly-D-lysine (MW, 10,000; Sigma), or Cell-Tak ( $3 \mu \mathrm{g} /$ coverslip; Biopolymers Inc.; Waite and Tanzer, 1981; Waite, 1983). The RGCs were also grown on 35-mm Falcon plastic culture dishes between circular islands of astrocytes. The islands of astrocytes were obtained by initially growing the astrocytes in $75-\mathrm{cm}^{2}$ culture flasks and transferring the astrocytes to cloning cylinders attached to the culture dish surface by Vaseline/paraffin. After the application of the cytosine arabinofuranoside, the cloning cylinders were removed, thus leaving behind an island of astrocytes.

After the initial plating of the RGCs, the medium in the culture dishes was not changed for $4-5 \mathrm{~d}$. After this, the medium was changed every 2-3 d. The medium was never completely replaced; instead, approximately $30-50 \%$ of the medium volume was aspirated and carefully replaced with warm $\mathrm{CO}_{2}$ equilibrated medium.

Identification of $R G C s$. The RGCs were positively identified by retrograde labeling with rhodamine-conjugated microspheres (Luma-flor; Katz et al., 1984; Ramoa et al., 1988). The labeling was accomplished by injection of these fluorescent microspheres into the optic tract, the A layers of the dorsal lateral geniculate nucleus (dLGN), or the optic nerve using a $1-\mu l$ Hamilton syringe attached to a micromanipulator. The injections were made $48-72 \mathrm{hr}$ prior to the removal of the retina. The injections ( $5-10$ injections of $1 \mu$ leach) were made midway between the region of the dLGN representing central vision and the representation of the monocular segment of the visual field (about $15^{\circ}$ azimuth, $\pm 2^{\circ}$ elevation). The location of the optic tract, optic chiasm, and optic nerve was identified by extracellular recording with an insulated tungsten electrode (impedance, $1-2 \mathrm{M} \Omega$ ). After locating these structures, four or five $1-\mu l$ injections of the microspheres were made into the respective structures.

Data acquisition and observation of neuron growth. The microscope was equipped with phase-contrast optics and a Dage MTI series 68 video camera system that provided 1024 horizontal scan lines. The output of the camera was recorded with either a Panasonic AG 6010 or AG 6050 time-lapse video cassette recorder. In most cases, the fluorescent signal was detected in the video images of the labeled cells.

Two approaches were used to follow the regeneration of the retinal ganglion cell neuritic structure. In the first approach, single labeled cells were followed longitudinally by continuous recording of growth on the time-lapse video system until the cell showed signs of deterioration. Because the addition of fresh serum-containing medium could induce changes in the growth of the neurons, time-lapse sequences were never begun just prior to or just after fresh medium was added (see Lcvin and Loskutoff, 1980, for description of one "fresh growth medium effect"). In the second approach, the redevelopment of the RGC neuritic structure was recorded by fixing every culture dish and coverslip from a particular dissociation at various times after plating. The cell cultures were fixed with either $5 \%$ acetic acid and $95 \%$ ethanol or $2 \%$ paraformaldehyde in a $0.15-\mathrm{M}$ phosphate buffer. The positions of the labeled cells were marked prior to the fixation, and the cells were systematically videotaped. In order to maintain a consistent spatial resolution in the analysis, the fixed cells were also videotaped and thus analyzed at approximately the same spatial resolution and with the same optical clarity. Analysis of the video data was accomplished by a PCVISION plus ${ }^{\mathrm{TM}}$ frame grabber (Imaging Technology Inc.) that was installed in an IBM PC/AT computer. The displayed images were captured, analyzed, and processed using in-house video analysis and processing programs.

Data analysis and calculation of Hausdorff dimensions. Tracings of the video images of the RGCs were made using a high-resolution video monitor with an optical mouse that allows a user to produce an overlay drawing of the neuron directly on the video monitor (Fig. 2). Neurite diameter information was not recorded in the overlay drawings. In regions where an inter-branch-point segment (hereafter called segment) was wide, the segment was approximated by a curve that passed along the center of the flattened region. The somata were not included in the overlay drawings; therefore, all the calculations of spatial parameters (total number of segments, total neurite length, Hausdorff dimension, etc.) did not incorporate the soma.

Video images of 25 (published) camera lucida drawings of postnatal cat retinal ganglion cells studied in situ (Maslim et al., 1986; Stanford, 1987a; Dann et al., 1988; Ramoa et al., 1988) were used to produce overlay drawings of these cells. These overlay drawings were made in the same manner as the overlay drawings produced for cells grown in culture. This group of 25 ganglion cells included three embryonic day 50-60 (E50-E60) cells, four postnatal day 0 (P0) cells, one P3 cell, three P5 cells, three P15 cells, four P31 cells, and seven adult cells. The reported morphological classes were $2 \gamma$-cells, $12 \beta$-cells, $8 \alpha$-cells, and 3 unclassified cells. The video images of the cultured retinal ganglion cells were made directly from the unperturbed coverslips and culture dishes. Once the tracings were complete, all quantitative analysis of structure was derived from the overlay drawings.

In order to assess the space-filling capacity and complexity of the neuritic patterns, we calculated the Hausdorff dimension of the patterns and the fractal dimension (or straightness) of individual neurite segments. The calculation of the Hausdorff dimension of two-dimensional neurite patterns and the use of this metric to reveal a space-filling growth strategy in cultured retinal ganglion cells have been described previously (Montague and Friedlander, 1989). For two-dimensional neurite patterns, this metric gives a measure of how well the ncurites cover a bounded planar region. In a given bounded planar region, as the spacefilling capacity of the elaborated neurite pattern increases, this measure will increase from a lower bound of 1 and approach the upper bound of 2. In general, this metric does not simply measure the area or volume occupied by the neurites, but measures how well the neurites fill in or cover a particular region. Details of the methods for calculation of the Hausdorff and fractal dimensions are presented in the Appendix.

\section{Results}

The retrograde labeling of the RGCs with fluorescent microspheres, in addition to the sparsity of the initial plating, allowed the unambiguous identification of the RGCs after the dissociation of the retina. Low- and high-power photomicrographs of freshly plated fluorescently labeled RGCs are illustrated in Figure 3. To avoid potential damage to the cells, the frequency and duration of observation under fluorescent illumination were kept to a minimum. The label typically persisted for as long as the cells were viable, but in some cases, the intensity of the fluorescent signal decreased with time in culture. A positively identified RGC is illustrated in Figure 4. Note the fluorescent label in the freshly plated cell and the elaboration of extensive neurites over time. 
The cells in our experiments generally attached to the substrate within hours of initial plating. While early attachment and survival of the labeled RGCs was good, only a subset of these cells (22-28\%) survived beyond $12 \mathrm{hr}$ and continued process extension. The cells began membrane ruffling and extension of lamellipodia within $24 \mathrm{hr}$ of attachment. In many cases, these early events were followed with time-lapse video microscopy. This early stage was characterized by continuous extension and retraction of membrane. This behavior has been noted for a variety of cell types in culture (Collins, 1978; Wessells et al., 1978; Dotti et al., 1988). Within $12 \mathrm{hr}$ of plating, many of these structures coalesced and extended away from the cell body as phase-dark processes. The processes did not simply extend, stop growing, and begin growth/extension at a later time; an active interplay of extension, retraction, and quiescence characterized the growth of the processes. In no cases did the cells divide after plating. This was not unexpected because previous studies of cat RGCs (Walsh et al., 1983; but see Johns et al., 1979) demonstrated that these cells are postmitotic by birth, and our studies were confined to RGCs from retinas of kittens $1-8$ weeks old.

After 3-7 d in culture, the RGCs developed neurite patterns reminiscent of RGCs observed in situ. Examples are illustrated in Figures 5 and 6 . The video images and drawings of three separate RGCs at 7-10 d postplating are illustrated in Figure $5 A-C$, respectively. The drawings of the same cells are shown in Figure $5 D-F$. Figure 6 shows drawings of eight RGCs that have achieved varying levels of neurite complexity. The cells in Figure 6, $A$ and $B$, are $3 \mathrm{~d}$ postplating, those in $C$ and $D$ are $7 \mathrm{~d}$ postplating, and those illustrated in $E-H$ are $10-20$ d postplating. The rich branching structure of the neurite arbors of these cells appears similar to the dendritic arborizations of RGCs observed in the intact retinas of cats (Maslim et al., 1986; Dann et al., 1987; Stanford, 1987a,b; Ramoa et al., 1988). This qualitative observation of a similar appearance of the dendrites was corroborated by a quantitative comparison of how the RGCs covered territory under the conditions afforded by the intact retina as compared with the conditions in our cell culture system. The distributions of the $H$ values for the two populations are illustrated in Figure 7 and are similar. The RGCs from intact retinas included cells of various morphological classes and different stages of development.

The dynamic nature of the individual neurite segments is illustrated by the video images taken from time-lapse video sequences illustrated in Figure 8. A detailed view of the sculpting of a neuritic arbor is shown in this figure. Each panel represents an image at approximately 30 -min intervals. Considerable growth and retraction of processes are evident. The arrowheads facilitate the tracking of a series of neurite segments that extend, retract, and branch over a 4 -hr period. This interplay of growth and retraction is typical of all of the individual cells followed in time-lapse sequences. By displaying the position of neurite segments and branch points, the number of neurite segments and the total amount of neurite arbor (total branch length) could

Figure 1. Schematic showing the preparation of the retinal neuron cultures. $A$, Eyeball was removed, washed, and cut around the limbic border. $B$. The retina was gently removed in a sterile calcium- and magnesium-free buffer solution and transferred to one of two enzyme solutions: (1) $0.1 \%$ collagenase (Sigma), 5.0 mM EDTA (Sigma), and 1.0\% BSA (Sigma) in Earle's balanced salt solution (EBSS; Gibco) without calcium or magnesium, or (2) $0.1 \%$ trypsin and $0.5 \mathrm{~mm}$ EDTA in calcium- and magnesium-free EBSS. The enzyme solution was equilibrated in a $37^{\circ} \mathrm{C}$, $5 \%$ $\mathrm{CO}_{2}$ incubator before the introduction of the dissected retina. $C$, After $12-17 \mathrm{~min}$ in the enzyme solution $\left(37^{\circ} \mathrm{C}, 5 \% \mathrm{CO}_{2}\right)$, the enzyme solution was pipetted away. $D$, One to $3 \mathrm{ml}$ of serum-supplemented (10\% fetal bovine serum, Gibco) basal minimum cssential medium (Gibco) was added to the retina to stop the enzymatic digestion of the connective tissue elements. A sterilized piece of filter paper (0.45- $\mu \mathrm{m}$ millipore) was placed on the nerve fiber layer. $E$. Enlarged view of the retina with the filter paper applied to the fiber layer. $G C L$, ganglion cell layer; $O N L$, outer nuclear layer; $R L$, photoreceptor layer; $N F L$, nerve fiber layer. $F$, After turning over the retina with the attached filter paper, another piece of filter paper was applied to the photoreceptor layer $(R L)$, and this layer was peeled off. Because of the prior enzymatic treatment, the RL peeled off as a unit This peeling eliminated all photoreceptors from the cultures. The peeling was repeated two to four more times to eliminate most of the other retinal cell types except for the RGCs and displaced amacrine cells (Shiosaka et al., 1984; Montague and Friedlander, 1989). However, because of the injections of the fluorescent microspheres into the dLGN, only RGCs were labeled. $G$, After the peelings, a relatively pure layer of RGCs was left attached to the filter paper. $H$. The RGCs adhering to the last piece of filter paper were suspended in HB101 medium (Du Pont) supplemented with $0.5-2.0 \%$ fetal bovine serum (Gibco), $20 \mathrm{~mm}$ glucose, $20-25 \mathrm{~mm} \mathrm{KCl}, 30-50 \mathrm{mg} / 100 \mathrm{ml}$ L-glutamine, and $26 \mathrm{~mm}$ bicarbonate. This HB10 medium was used as the growth medium for the retinal cultures. $I$, The cells were collected and spun at $70 \times g$ for about 5 min. The supernatan was removed, and the cells were resuspended in the HB101-based medium, gently filtered through a 45- $\mu$ m sterile stainless-steel mesh, plated onto $35-\mathrm{mm}$ Falcon dishes or onto glass coverslips equipped with small paraffin pedestals, and allowed to attach for $1-2 \mathrm{hr}$ in a $37^{\circ} \mathrm{C}, 5 \% \mathrm{CO}_{2}$ incubator maintained at $98 \%$ relative humidity. $J$, Approximately $1 \mathrm{hr}$ later, the coverslips containing the attached ganglion cells were transferred to culture wells containing a confluent layer of astrocytes derived from embryonic rat cerebral cortex (McCarthy and deVcllis, 1980), and the culture dish containing the coverslip was transferred either to the microscope or back to the incubator. Growth of the astrocytes was halted by the pulsed application of the mitotic inhibitor cytosine arabinofuranoside (10 $\mu \mathrm{M}$; Sigma). $K$, The environment around the microscope stage was maintained at $35^{\circ} \mathrm{C}$ and $5 \% \mathrm{CO}_{2}$, and the growth of the cells was monitored with a time-lapse video cassette recorder.

Figure 2. Method of estimating the Hausdorff dimension of the neurite patterns. $A$, Phase-contrast video image of a ganglion cell growing on the glass coverslip. The arrowheads indicate non-neural cells. $B$, Overlay drawing of neurite pattern superimposed on the video image. $C$, Overlay drawing alone. $D-G$, After the overlay drawing was stored in computer, it was used to produce the Hausdorff dimension. $E$ is a line drawing of the video image shown in $D$. The program covers the overlay drawing with a sequence of grids composed of square boxes (side length $d$ ) and counts the number of boxes intersected, $k(d)$, for each grid that is used. To avoid problems associated with the use of a square grid, the orientation of the grid relative to the overlay drawing was randomly varied, and the average of the number of boxes intersected was used as the value of $k(d)$ for each grid. This method establishes the relationship between $d$ and $k(d)$ over a range of values, and the Hausdorff dimension is taken to be the negative value of the slope of the regression line fitted to the plot of $\log (k(d))$ versus $\log (d)$. (See Appendix.) The minimum and maximum values of $d$ that can be used to establish the relationship between $d$ and $k(d)$ depend on the spatial resolution of the overlay drawing relative to the size of the neurite pattern.

Figure 3. Initial labeling of dissociated retinal ganglion cells. $a$ and $b$, Low-power bright-field and fluorescent photomicrographs of labeled ganglion cells immediately after plating. Magnification, $200 \times . c$ and $d$, Higher-power photomicrograph of two labeled ganglion cells that became attached during the dissociation. Magnification, $2000 \times$. 


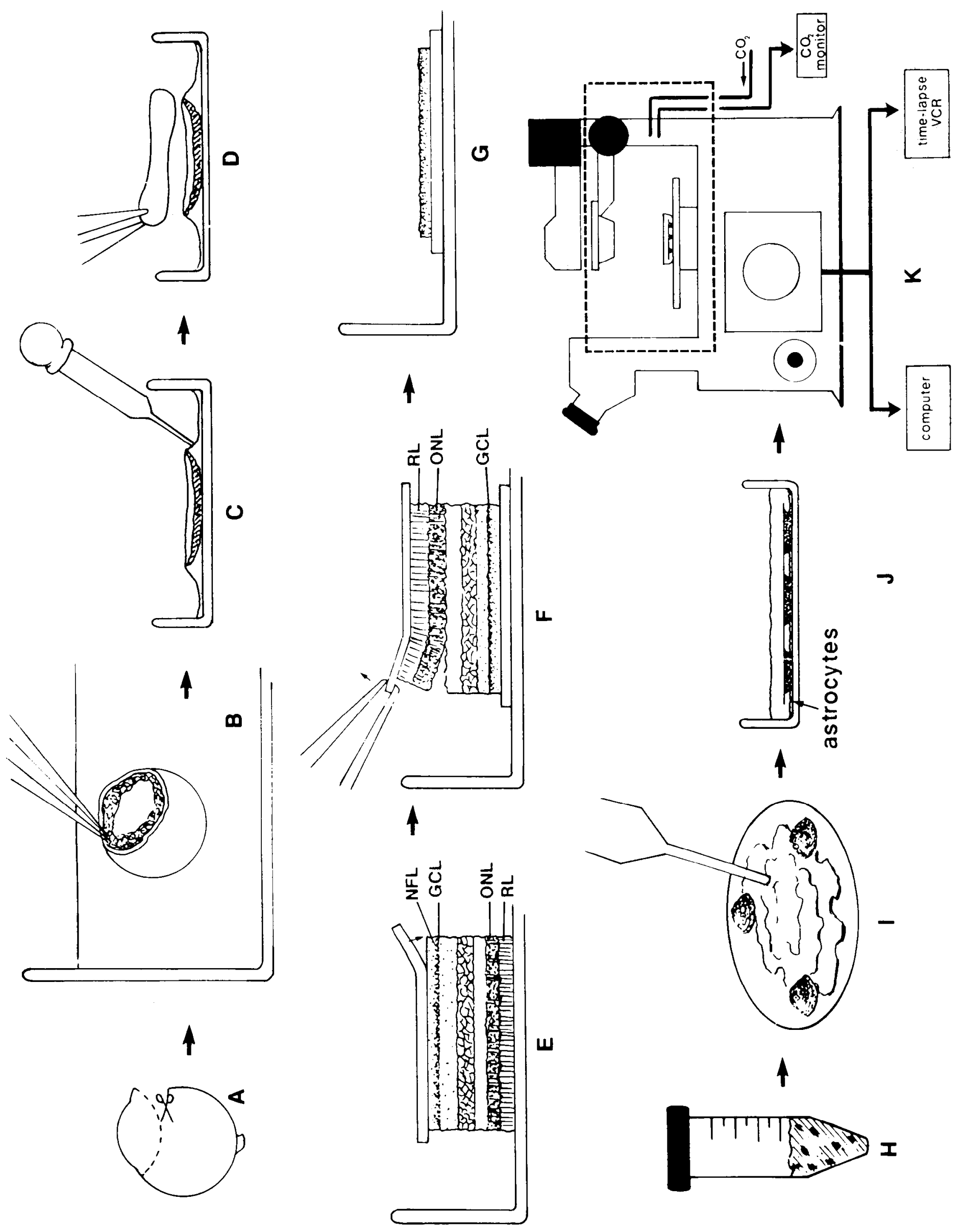




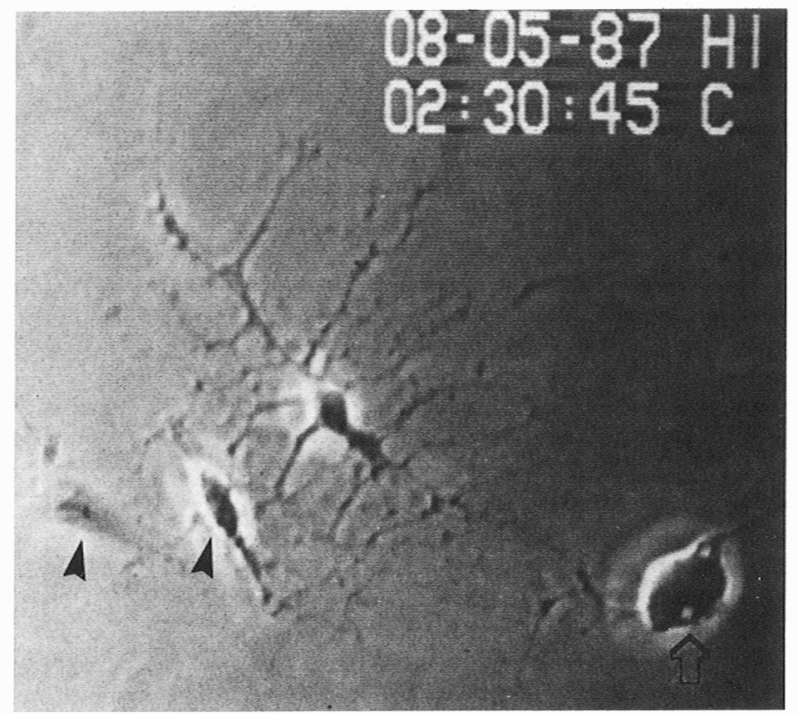

A

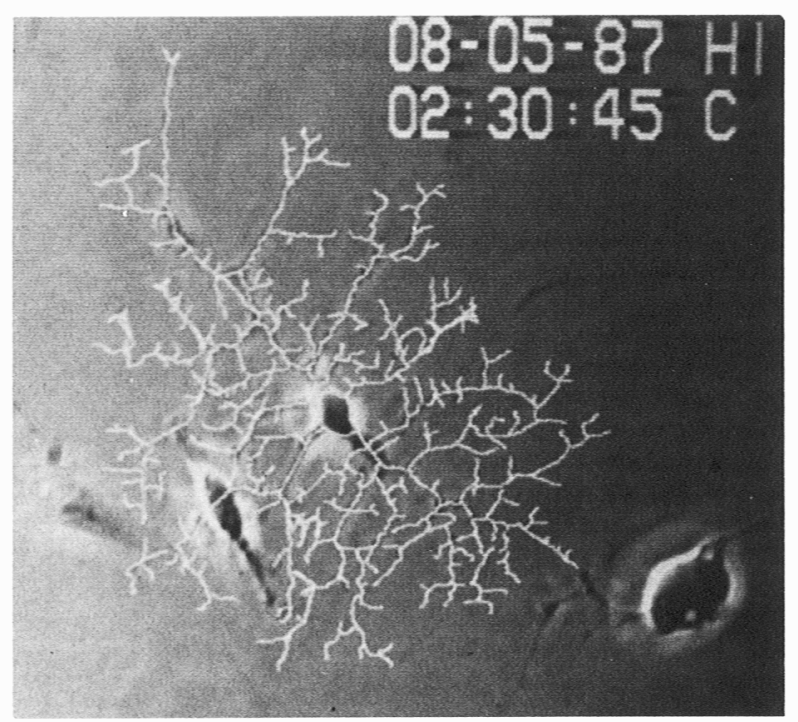

B

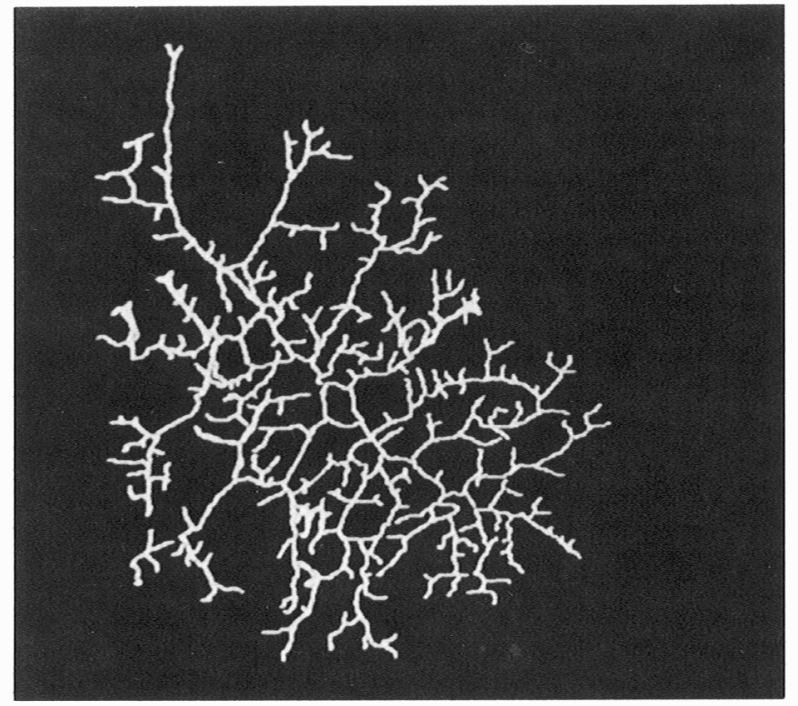

C

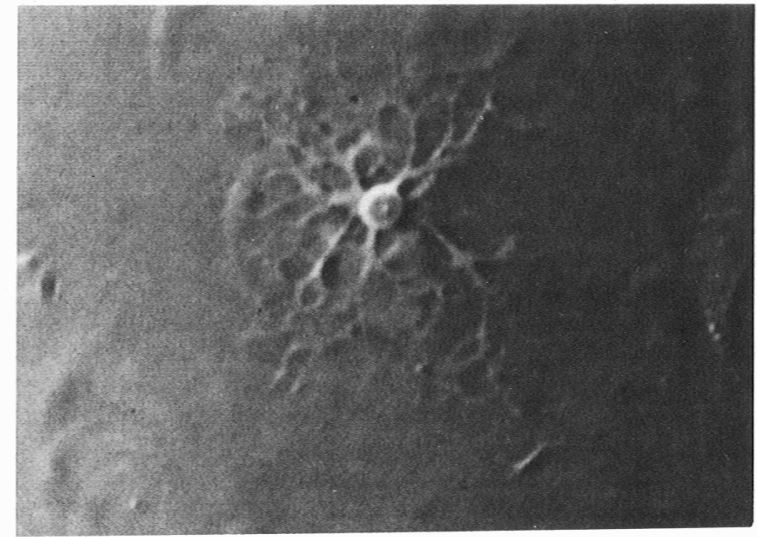

D

E
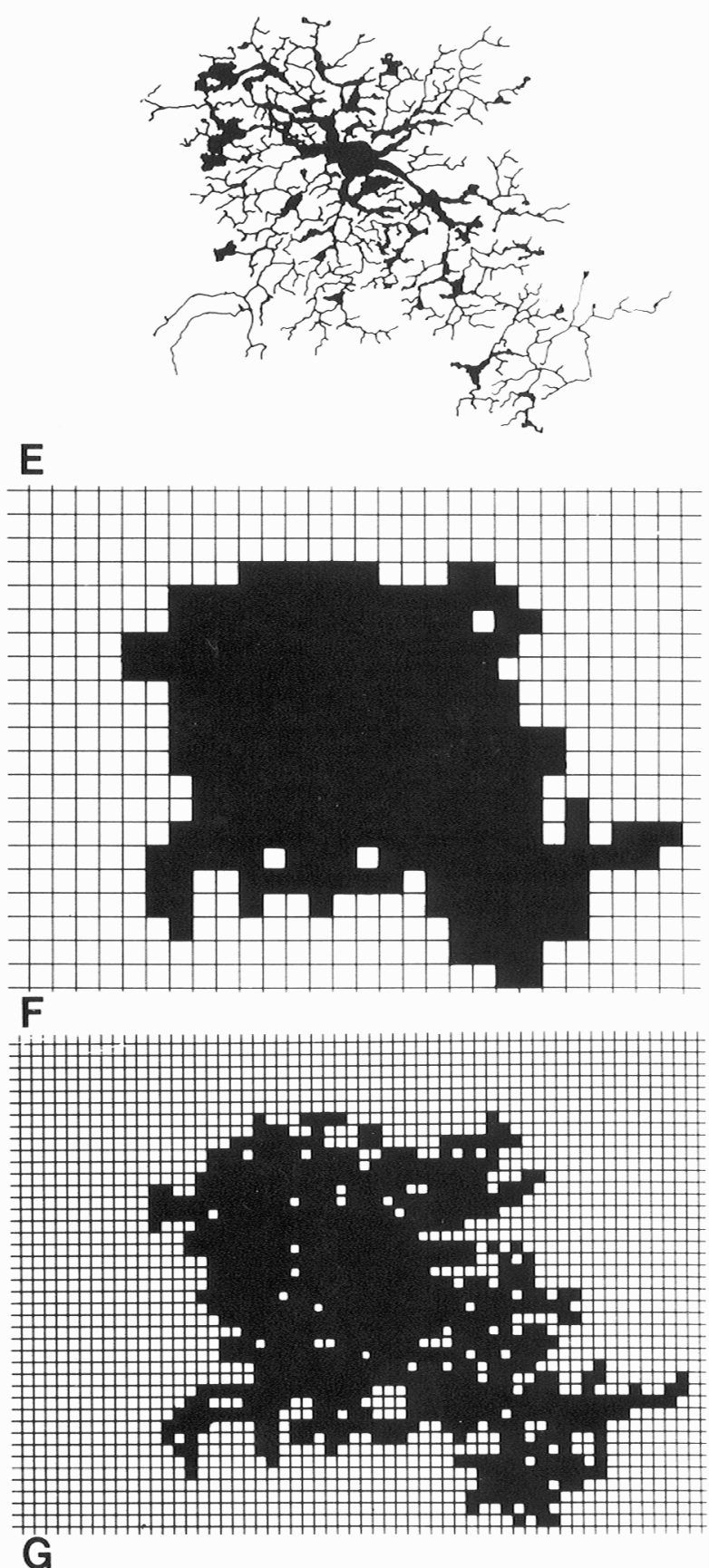

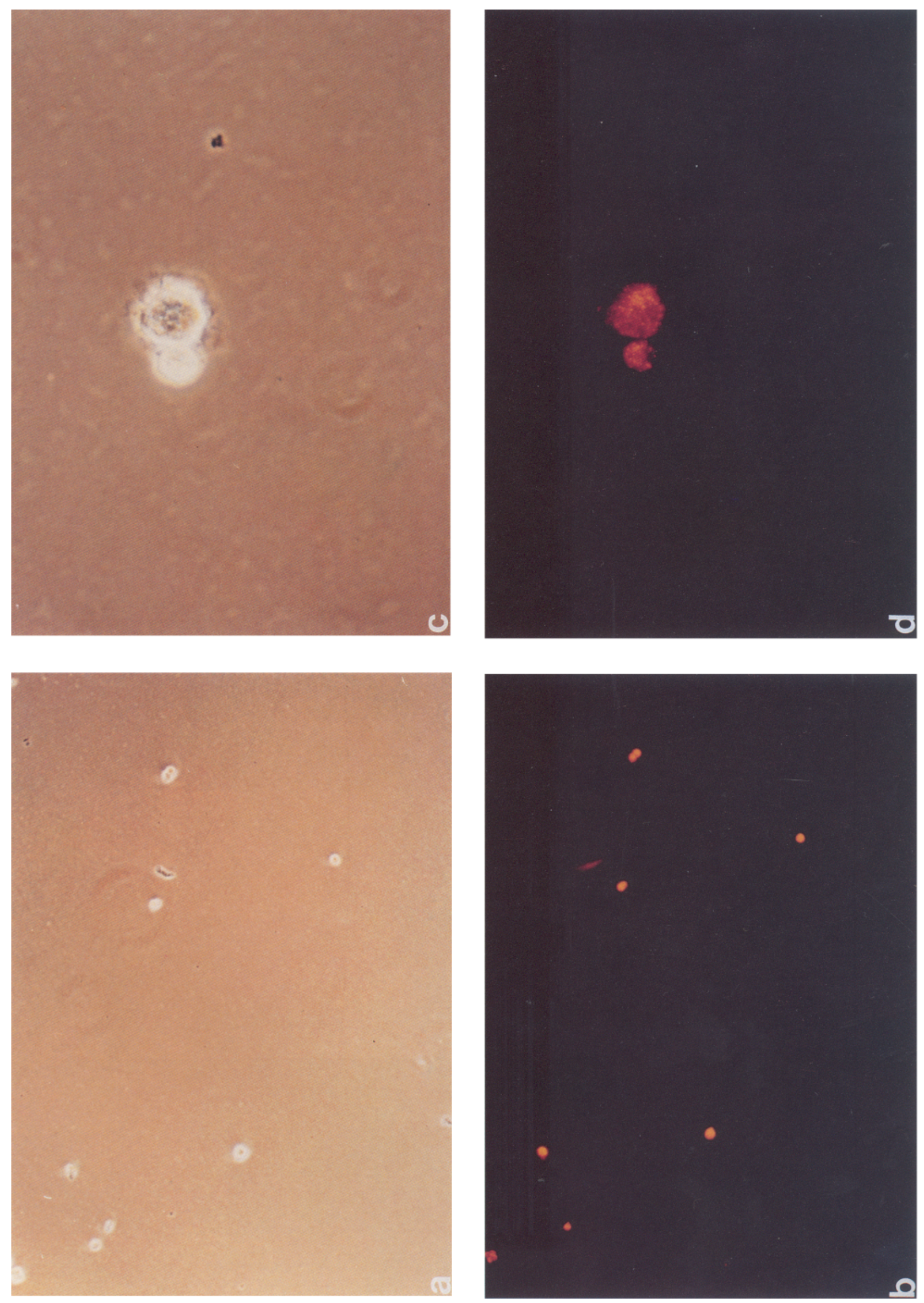

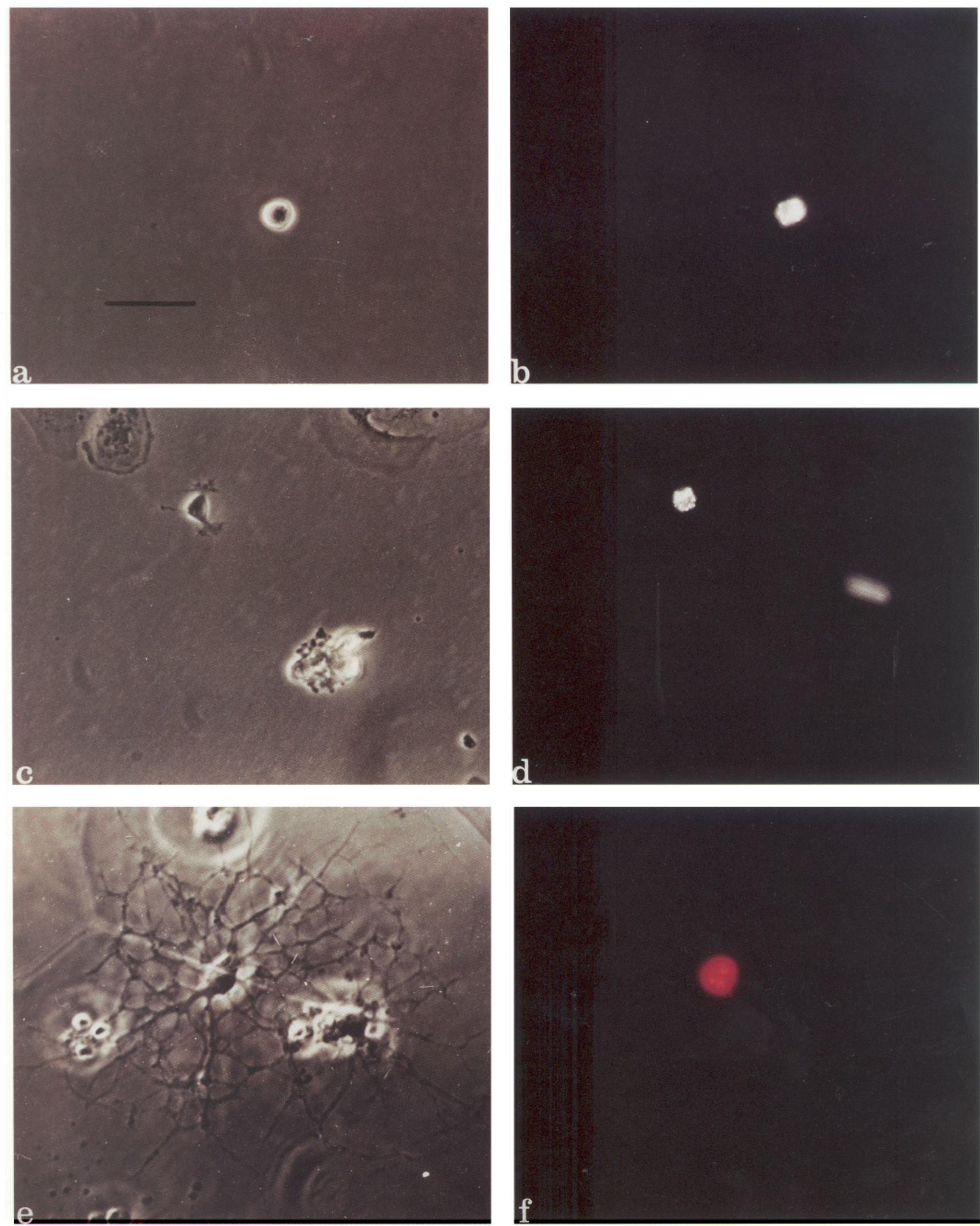

Figure 4. Examples of morphology and labeling at various times in culture. $a$ and $c$, Isolated and labeled RGCs after $2.5 \mathrm{hr}$ and $7 \mathrm{hr}$ in culture, respectively, growing on poly-L-lysine coated plastic culture dish between circular islands of astrocytes (see Materials and Methods). $b$ and $d$, Respective fluorescent images. $e$ and $f, \mathrm{RGC}$ after $8 \mathrm{~d}$ in culture, with its fluorescent image, respectively. Note the presence of a neighboring unlabeled cell with RGC morphology. 

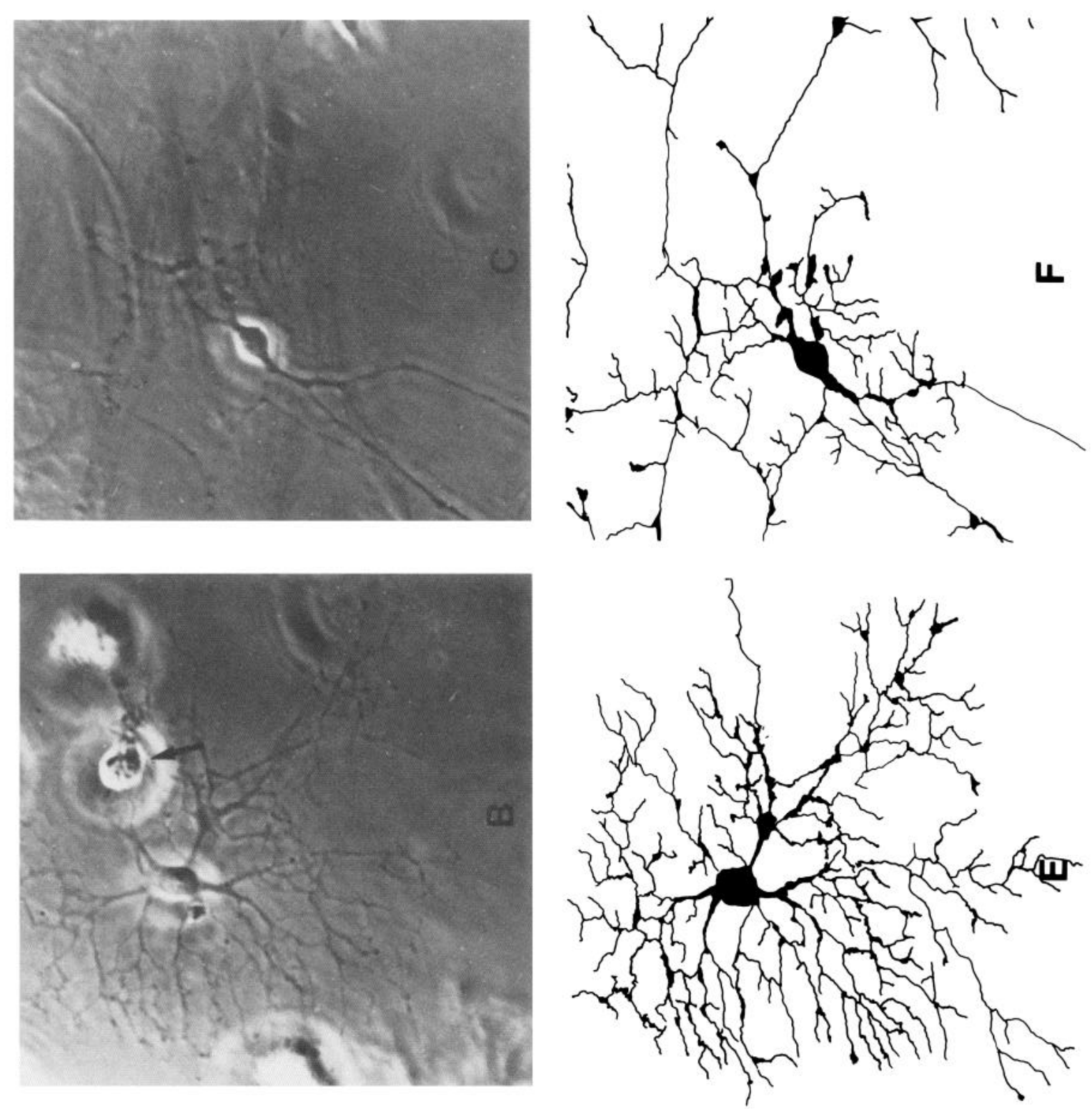

ธิ

डi

을

迅造范

品

过它

를

站

这.

青客

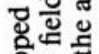

을용

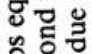

은.

宽言

造密

क

$\checkmark$ 모

Q

도요무

웛

吨

봉

물

눙흉형

흐를

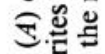

远位

응.

告

드

ड़०

드옫

이드
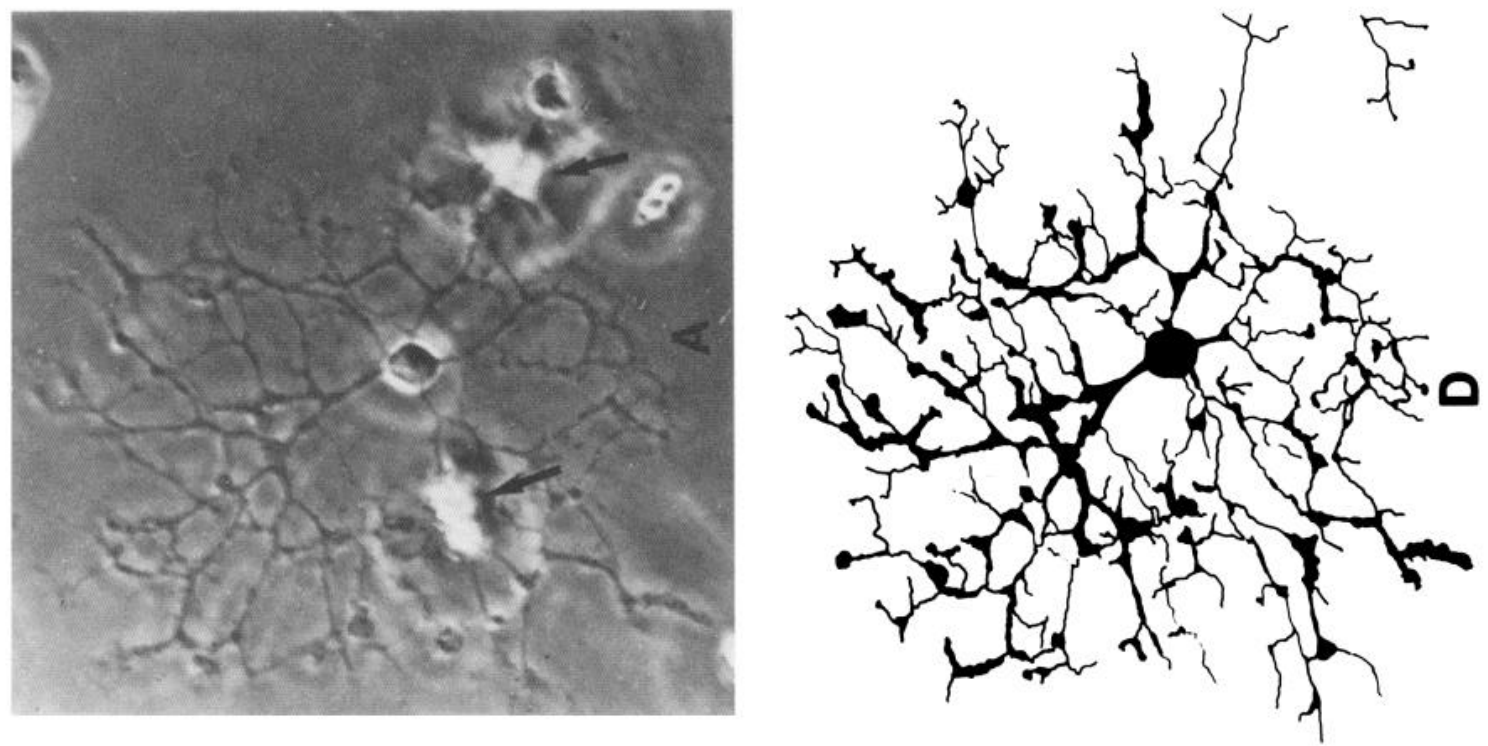

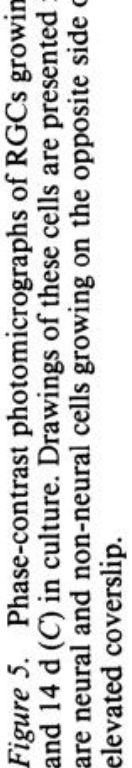




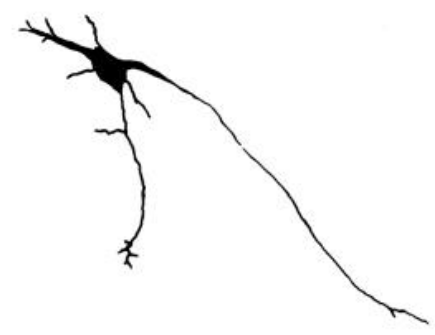

A

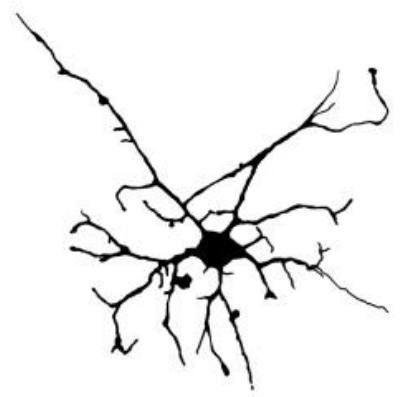

C

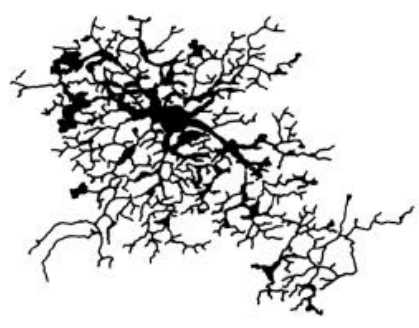

E

Figure 6. Drawings of cultured RGC morphology at various times after plating. $A$ and $B$, Less than $72 \mathrm{hr} ; C$ and $D, 4-5 \mathrm{~d} ; E-H,>10$ d. Scale bar, 100 $\mu \mathrm{m}$.

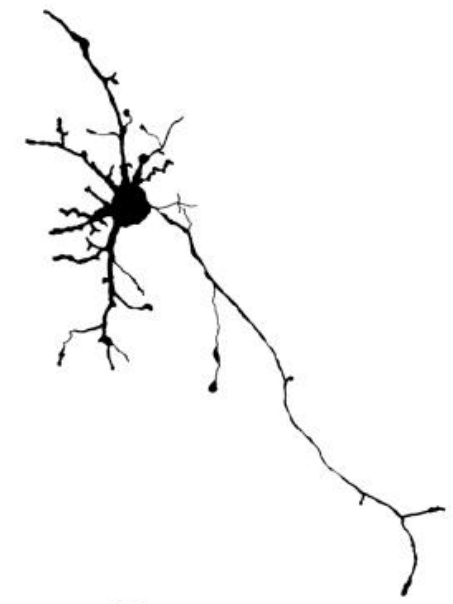

B

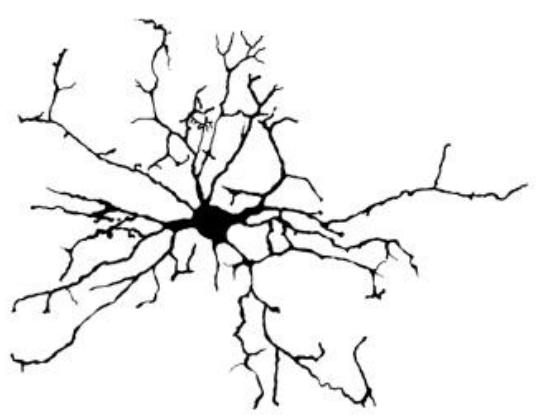

D

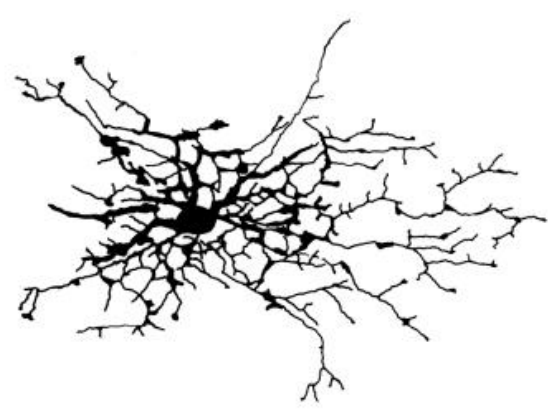

$\mathbf{F}$

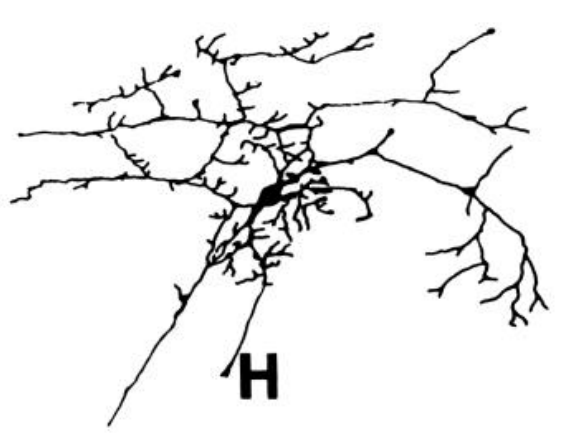


be followed quantitatively for a given cell over time. The parallel trend between the normalized total segment length $(T)$ and the normalized number of segments $(N)$ is illustrated in Figure 9. This trend was observed for each of the six RGCs followed in time-lapse sequences. The linear trend indicates that the RGCs tend to elaborate segments of some stable mean length. This idea was corroborated for the entire population of neurite patterns by plotting $T$ versus $N$ (Fig. 10).

Close examination of the time-lapse data revealed that segment growth can switch between periods dominated by the addition or subtraction of segments of a stable mean length and shorter periods $(2-4 \mathrm{hr})$ when the growth of existing segments is a major contributor to changes in the total mass of the neuritic pattern. However, the mean segment length for the entire population was stable, and overall the growth was dominated by the addition of segments of a stable mean length.

To assess how well the neurite patterns of the isolated RGCs covered a restricted region of space, we calculated the Hausdorff dimension, $H$, of the patterns. The Hausdorff dimension of the neurite patterns increased with time in culture (Fig. $11 A$ ), with $H$ saturating around 1.7 . In order to test the respective contributions of the total neurite length and the number of segments to the $H$ value of the neuritic patterns, $H$ was plotted as a function of the normalized number of segments, $N$, or the normalized total neurite length, $T$ (Fig. $11 B$ ). After about $4 \mathrm{~d}$ in culture, $H$ varies between 1.6 and 1.9 , independent of $T$ and/ or $N$.

The straightness measure or fractal dimension ( $D$; see Appendix) was used to assess the contribution of the eventual straightness of the segments to the Hausdorff dimension of the overall neurite pattern. This measure (D) was used because the Hausdorff dimension $(\mathrm{H})$ of these two-dimensional neurite patterns is insensitive to the details by which a restricted region is covered. Figure 12 illustrates the application of this metric to the evaluation of tortuosity of the paths followed by individual neurite segments. Figure $12, A$ and $B$, illustrates the overlay drawing of an RGC's neuritic arbor and an approximation of the arbor where each segment is replaced by a line segment between sequential branch points, respectively. The distributions of the fractal dimensions of all the individual segments from the cell shown and from all of the individual neuritic segments for the population of cells studied are illustrated in Figure 12, $C$ and $D$, respectively. As evaluated by this straightness measure, the RGCs elaborated segments that deviated very little from relatively straight paths. $D$ clusters near 1 both for the individual cell shown and for the entire population. Thus, the neurite segments between branch points are quite straight, implying that the arborizations of individual RGCs do not achieve their high efficiency of territorial coverage (indicated by a mean $H$ of 1.7 ) by individual segments following circuitous paths. Rather, the coverage is accomplished by strategic positioning of segments within the territory defined by the cell's neuritic arbor.

Another indication of the mechanisms that contribute to efficient coverage of space is the strong self-avoidance exhibited by growing neurites. That this occurs is evident from static images of the cells that have elaborated their neurites (Figs. 5, 6) as well as from observations of time-lapse sequences of the actively growing neurites (Fig. 9). Self-crossings of neurites were observed in $0.05 \%$ of cases ( $n=2500$ segments), and the dynamics of this process were seen from apparent contact-induced retraction of processes during periods of active growth. Thus,
A

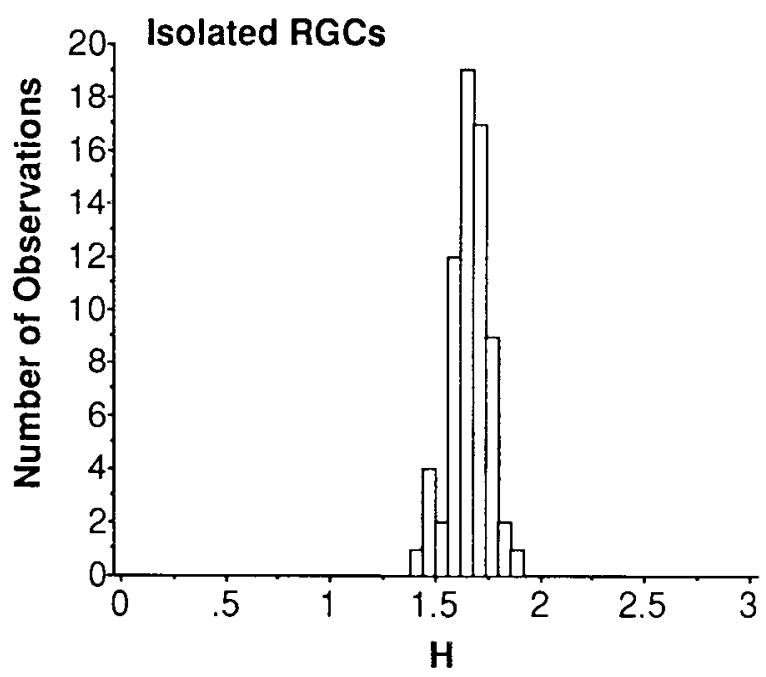

B

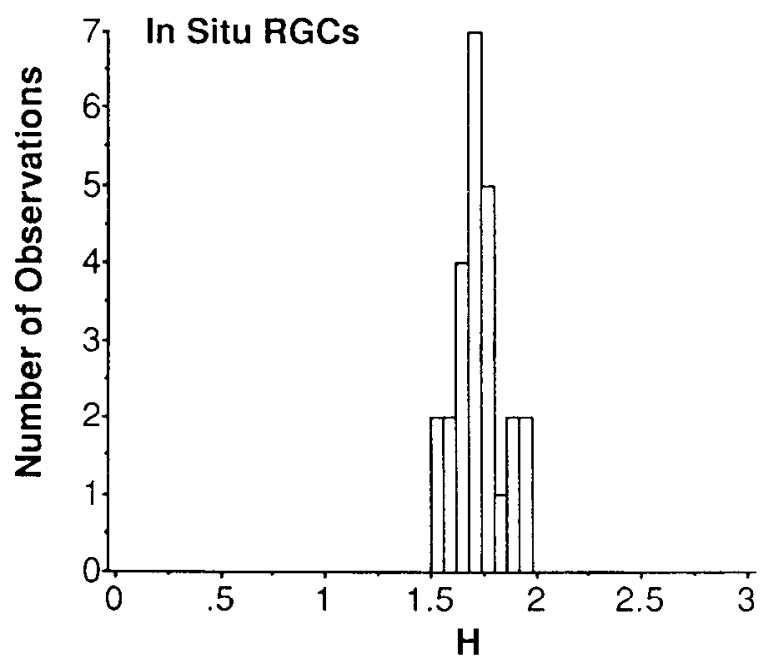

Figure 7. Frequency distribution of $H$ values for cultured $(A)$ and in situ $(B)$ RGCs. The mean for the in situ cells is somewhat larger; however, the data for the cultured RGCs include $H$ values for cells in culture for only a short time $(<72 \mathrm{hr})$.

as growing tips of neurites became bounded by their cell's own arborization, they covered successively smaller areas of available space by adding new segments. This could possibly account for the limited arbor diameters observed in culture $(\bar{x}=184$ $\mu \mathrm{m}$; range, $110-280 \mu \mathrm{m})$. In the intact retina, the actions of afferent input may modulate the self-limiting neuritic diameters observed for RGCs grown in isolation. That this process was indicative of the RGCs and not a generalized effect of the culture system was evaluated by observing the growth of neurites from neurons obtained from other CNS sites in the central visual pathways of the same animals. Visual thalamic (LGN) and visual cortex neurons (Montague and Friedlander, 1989) were studied. These cells elaborated neurite patterns characteristic of those observed in vivo, and qualitative observations of the neurite patterns formed by these cells suggested that they did not fill space efficiently. Measurements of the cells' Hausdorff dimensions $(\leq 1.3)$ corroborated the apparent poor coverage of space. 

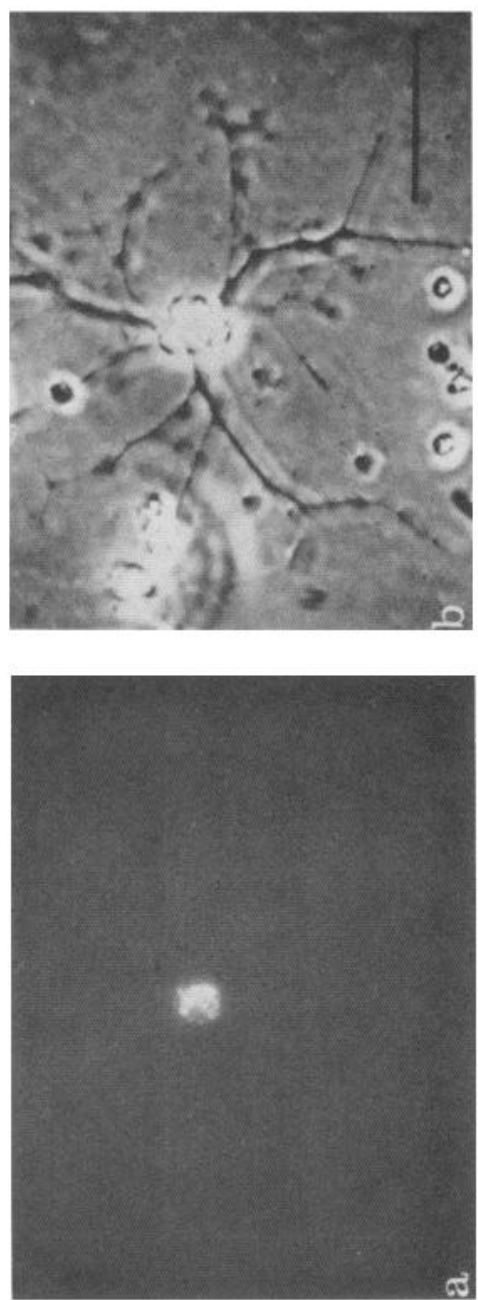
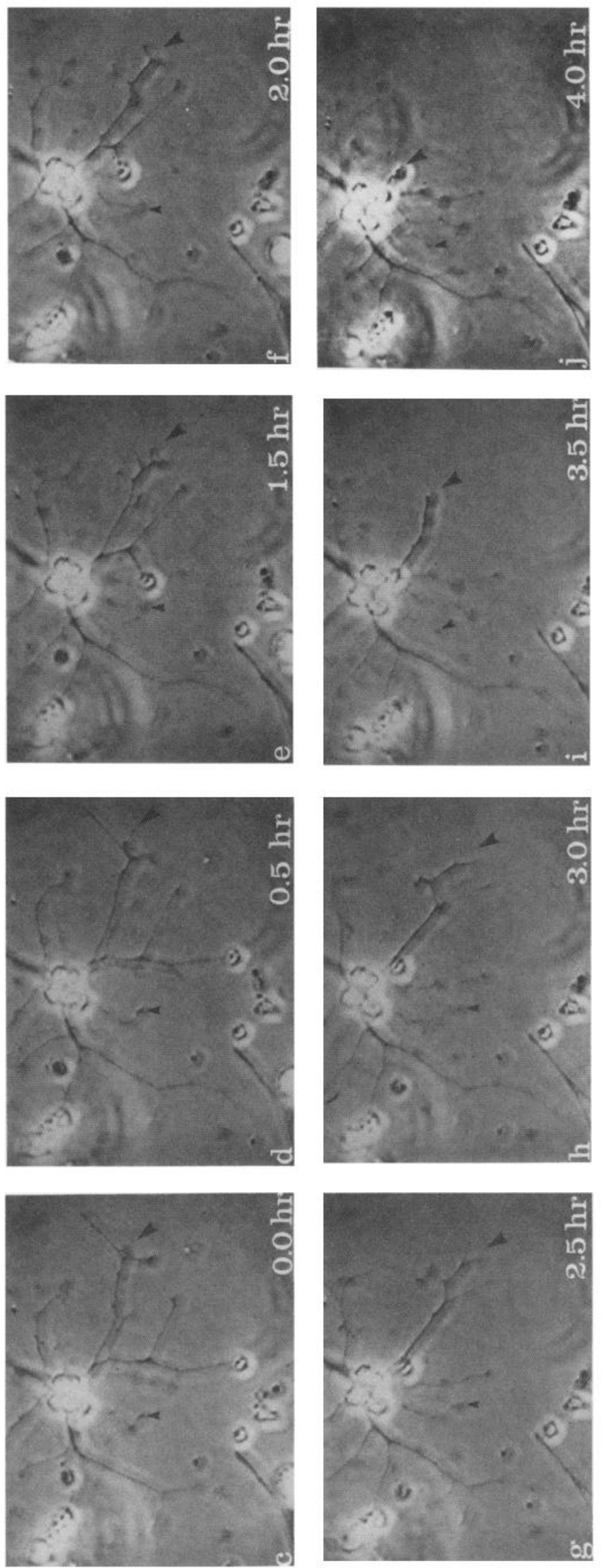

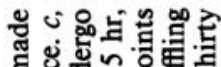
的员

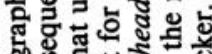
物 象远 웡

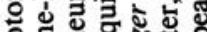
혀의 $\&$. जि 我记 \&

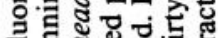
压. 등

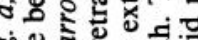
की के

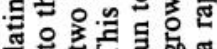

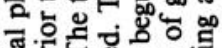
吅

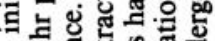

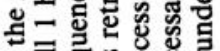

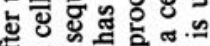

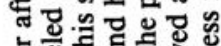
上纯 즈의 ता

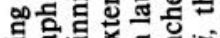

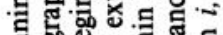

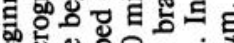
هั. 응 눙

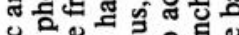

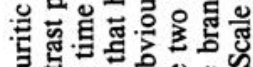

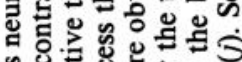

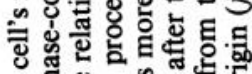
동 $\pi .40$ क力口. 0 . ‥ क छ 哥 旸

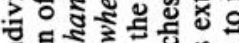
G.

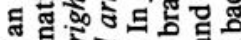
若

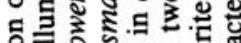
월 边政

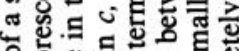

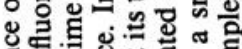

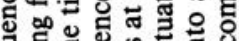
. ष्ञ o

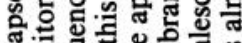
1

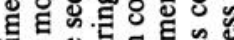
品

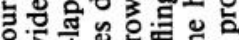

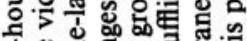
은 응 ड्य 山 ह $\infty$ 造

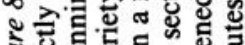

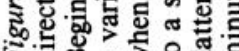




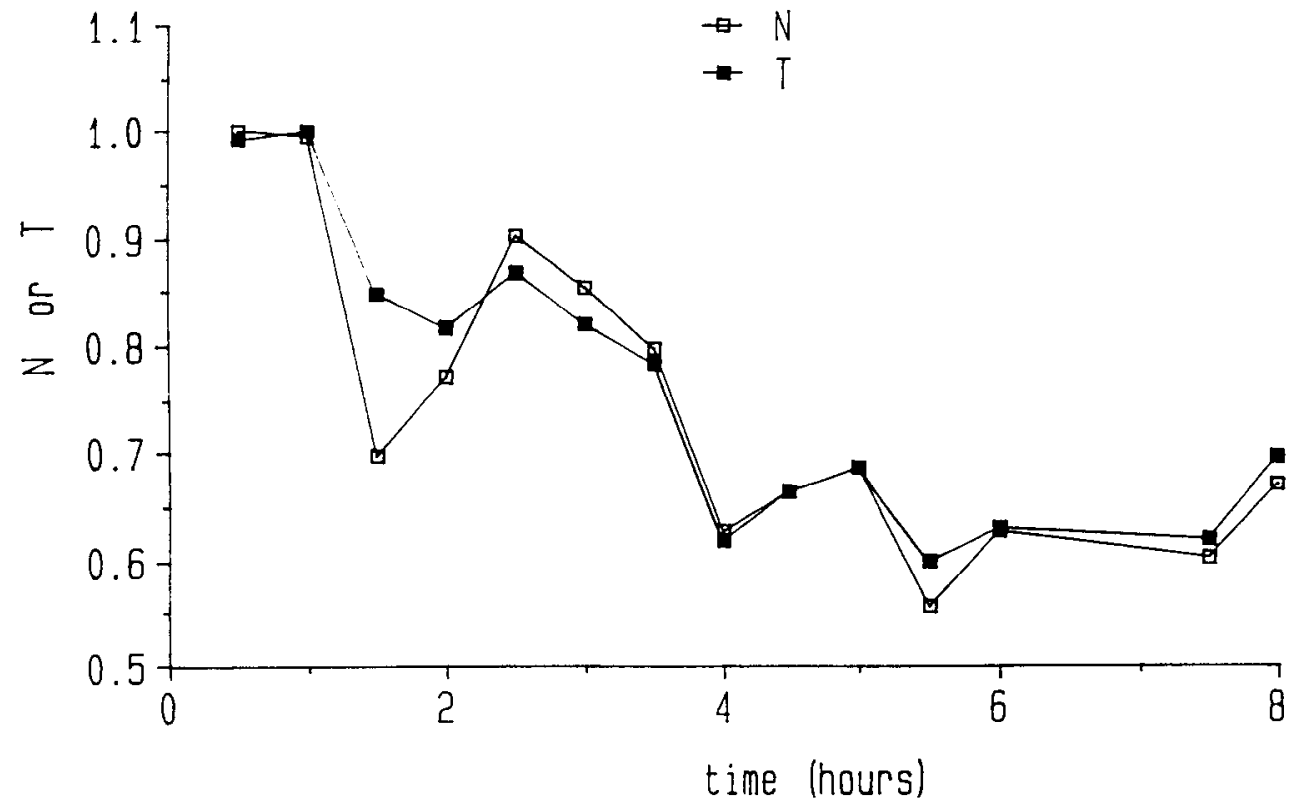

Figure 9. Time-lapse data showing parallel trend between the normalized number of segments $(N)$ and the total neurite length $(T)$. The entire sequence represents $7.5 \mathrm{hr}$ beginning at $91 \mathrm{hr}$ after the initial plating. The total mass of the neuritic arbor is taken to be the total length (in $\mu \mathrm{m}$ ) of all neurites belonging to the arbor. Both the total mass and the number of segments were normalized to the largest value obtained during the time sequence. The total mass for the neurites of this cell varied from 1231 to $2042 \mu \mathrm{m}$ during this sequence. The number of segments varied between 91 and 163 during the sequence. Note the pulsatile (and parallel) time course of number of segments and the total mass.
The diameters of the neuritic arborizations of the isolated RGCs ranged from 110 to $280 \mu \mathrm{m}$ (Fig. 13). These values were obtained from cells from 7-21 d postplating. Little change in diameter occurred during this period, though extensive remodeling of the arborizations continued primarily by repositioning of neurite segments of a stable mean length. That the isolated RGCs did not continue to expand the extent of their neuritic arborizations indefinitely suggests that self-limiting intrinsic processes restrict the size of the arbor that the cell can support. Thus, while competitive interactions between processes of neighboring cells play an important role in determining the overall extent of a cell's dendrite arborization in situ (Linden and Perry, 1982), intrinsic mechanisms may also regulate the upper bound of the process.

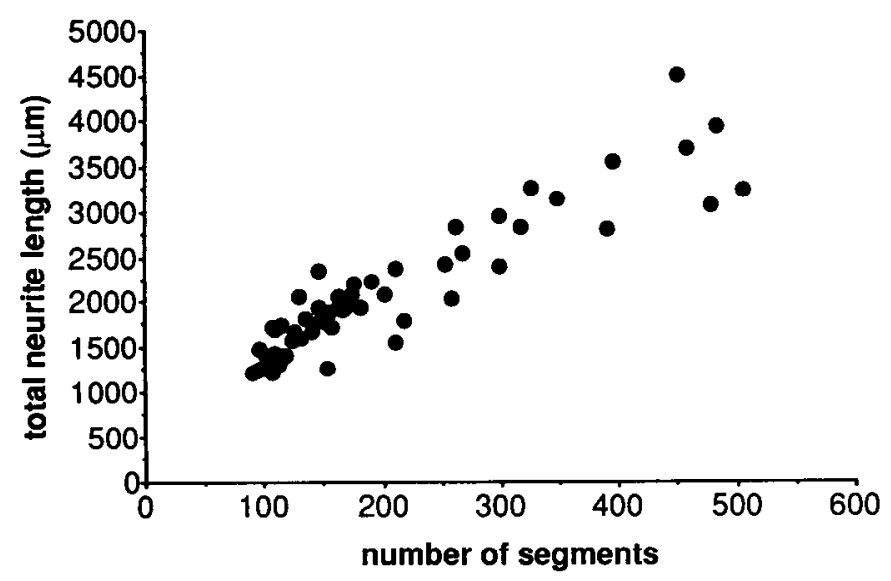

Figure 10. Total neurite length versus total number of segments for all neurite patterns observed after $72 \mathrm{hr}$ in culture. A linear trend is observed between these two parameters $(r=0.91 ; n=64)$.
A

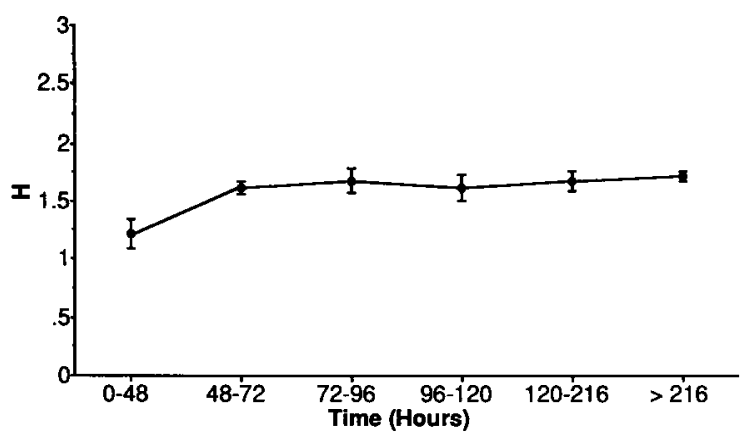

B

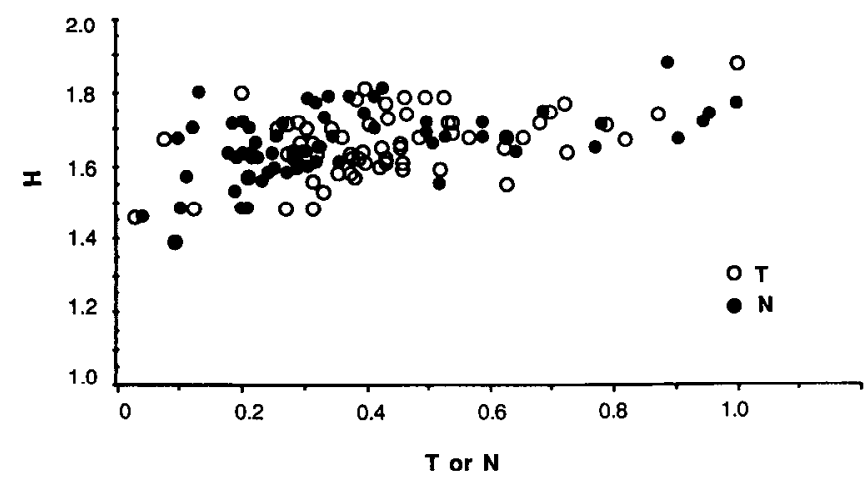

Figure 11. Hausdorff dimension, $\mathrm{H}$, as a function of time in culture and amount or number of ncurites. $A, \mathrm{H}$ versus time in culture. The cells have been collected into six groups based on time in culture. Error bars indicate SEM. $B, H$ versus the normalized total neurite length, $T$, or number of inter-branch-point segments, $N$, for all neurite patterns after $72 \mathrm{hr}$ in culture. 

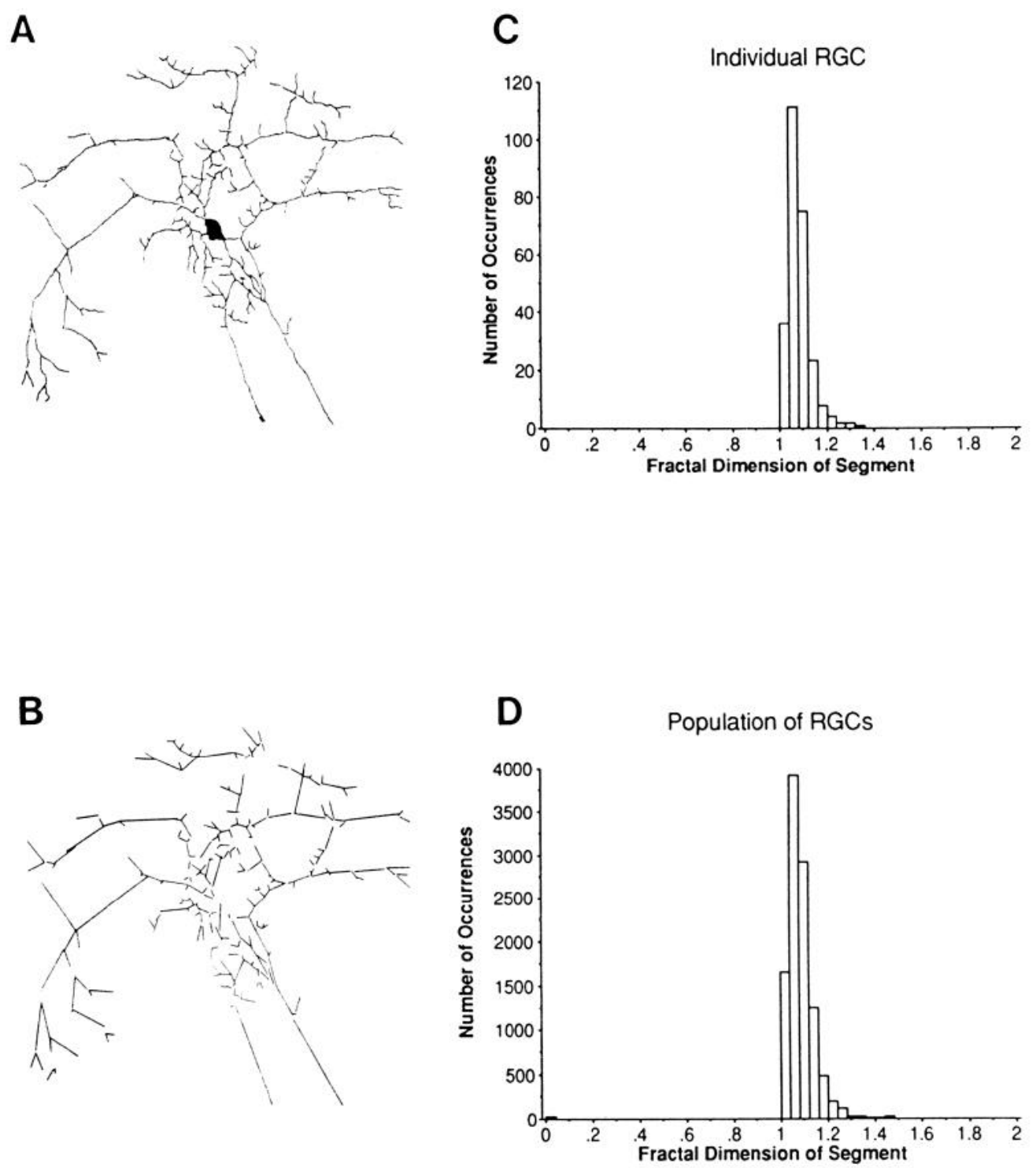

Figure 12. Distributions of fractal dimension, $D$, of individual neurite segments of isolated RGCs. $A$ and $B$ are digitized drawing and straight-line approximation of an example RGC's neurite arbor, respectively. Histograms in $C$ and $D$ illustrate the relative straightness of the individual neurite segments of the individual RGC illustrated and the entire population of RGCs studied, respectively. Note the clustering of the distribution near 1.0 , indicating that the individual cell covers space by strategic positioning of relatively straight neurites versus development of tortuous paths by individual neurite segments.

of the branches in a given cell was rare, and the RGCs expressed

\section{Discussion}

\section{Conclusions}

Five major observations can be made concerning the elaboration of neurites by isolated mammalian RGCs in cell culture: (1) Although the cells were obtained at ages when considerable physiological and morphological development had occurred, they maintained their ability to reexpress neuritic arborization patterns characteristic of RGCs in the intact retina. (2) This reexpression proceeded in the absence of environmental cues normally present in the intact retina and in the absence of interactions with target tissue. (3) The isolated RGCs in culture efficiently covered territory with their neurites primarily by strategically positioning new segments of a stable mean length, as opposed to process extension. In contrast, other types of neurons in the same culture system (e.g., cortical neurons) covered territory primarily by neurite extension rather than by addition of new segments. (4) The neurite segments produced by the isolated RGCs tended to be straight as assessed by the straightness measure of Katz and George (1985); the occurrence of self-crossings a constrained range of neuritic diameters $(110-280 \mu \mathrm{m})$. (5) The Hausdorff dimension of the neurite patterns increased with time in culture. However, after about $4 \mathrm{~d}$ in culture, this metric of areal coverage saturated between 1.6 and 1.9 and was independent of the number of segments and/or the total neurite length of the arbor.

\section{Effects of culture conditions}

Several lines of evidence suggest that RGCs are the source of cells used in this study. First, though many cells successfully attached and grew in our cell cultures, we restricted our analysis to fluorescently labeled cells indicating that they had a projection axon in the optic tract (see Materials and Methods). Second, the labeled cells developed neurite structures that appeared qualitatively similar to those of RGCs in situ. Third, the coverage of territory by neurite arbors was similar for the cultured cells and RGCs from intact retinas (as evaluated by Hausdorff dimension measurements). While these similarities do not prove that these cells have remained identical to RGCs, when consid- 
ered together they suggest that the cells do not change drastically. As previously demonstrated, a variety of phenotypic features can change in cell culture, and our system of growing individual isolated RGCs is clearly different from the in situ condition that allows for temporally and spatially orchestrated interactions from neighboring cells, afferents, and target tissue (Maslim et al., 1986; Dann et al., 1987; Ramoa et al., 1988). However, elimination of these interactions was precisely the goal of our experiment in order to evaluate the intrinsic capacity of individual RGCS to elaborate morphology. It is possible that other properties of these cells that we did not evaluate, such as neurotransmitter synthesis or ion channel function, are different from those of RGCs in situ. Moreover, when under the influence of neighboring cells and matrix in the intact retina, the intrinsic strategy for coverage of territory by RGCs is subject to modulation by the various environmental factors and may differ from that observed in culture.

In the intact retina, RGCs elaborate somatic-dendritic structure that allows them to be readily assigned to specific morphological classes that are discriminated primarily based upon dendritic branching patterns (Stone, 1983). When retinal eccentricity is taken into account, soma size is also a fairly reliable indicator of cell class. In our experiments, RGCs were retrogradely labeled by injections of tracer into the optic tract or throughout the layers of the dLGN. No attempt was made to restrict the harvesting of cells with respect to retinal eccentricity, soma size, or dendritic structure. Thus, our initial labeling probably included most morphological classes of RGCs. Indeed, when these cells reelaborated their neurites in cell culture, they developed the morphological characteristics of several of the major cell classes $(\alpha, \beta$, and $\gamma$; see Figs. 5,6$)$. It is possible that these cells reexpressed in vitro the particular neuritic morphological pattern that they had initially developed in vivo, thus remaining committed to a specific cell class. Alternatively, under our culture conditions, the cells may develop neurite patterns characteristic of an entirely different class independent of their initial differentiation in vivo. However, reexpression of dendritic structure under the control of intrinsic signals is clearly sufficient for these cells to develop characteristic RGC morphology.

Another potentially problematic issue is the degree to which our culture conditions impose aberrant morphology or select for a particular subpopulation of cells. Our data comparing the Hausdorff dimensions of our cultured cells to RGCs from intact retinas and to cells from other CNS sites cultured in our system address the first point. These values are similar for isolated RGCs and RGCs from intact retinas. Neurons from other CNS sites have different $H$ values and exhibit different growth strategies. These observations suggest that our culture conditions are not the primary determinant of development of RGC neurite structure. Whether subpopulations of RGCs, possibly more robust in the face of tissue trituration and cell isolation, are selected during our isolation procedure is less certain. Because our acceptance criteria included retrograde labeling, successful attachment, growth over several days, successful plating in isolation from neighboring cells, and capture by our image system, the number of cells analyzed was small $(n=48)$. However, the morphological variety exhibited by these cells was rich. This heterogeneity was observed under a variety of culture conditions, including the use of different substrates. Although the strategy for territorial coverage exhibited by the RGCs in our study is stereotyped, the cells can still achieve drastically different final morphology (see Fig. 6). Thus, this strategy appears

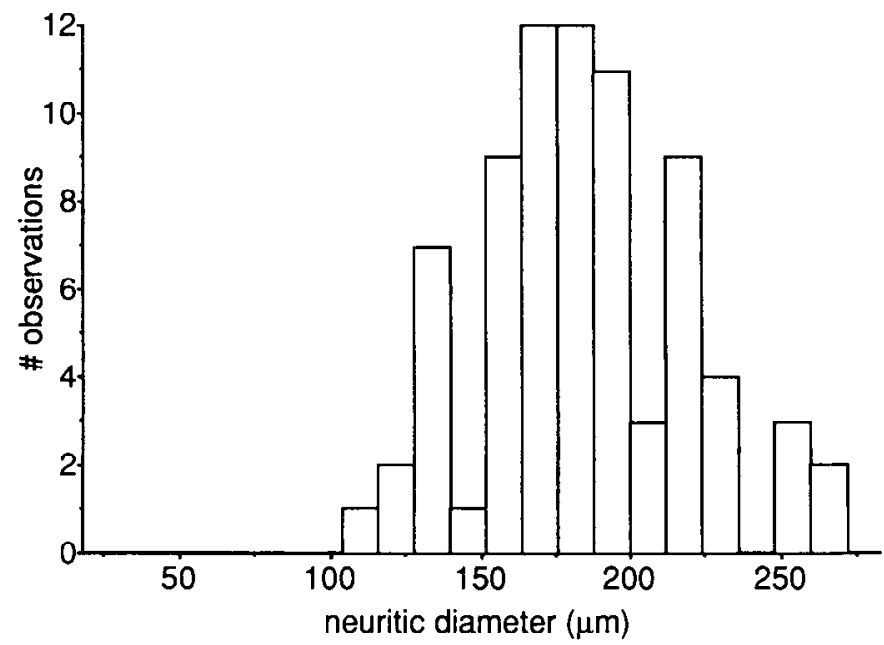

Figure 13. Histogram illustrating diameters of dendritic arborizations of isolated RGCs grown in cell culture. Measurements were made after $72 \mathrm{hr}$.

to be indicative of all the cultured RGCs independent of other factors that influence the observed morphological heterogeneity.

\section{Regeneration of morphology after removal of processes and environmental cues}

Ours is not the first demonstration that mammalian RGCs from postnatal animals can survive in cell culture (Leifer et al., 1984; Lipton, 1986; Raju and Bennett, 1986; Armson et al., 1987; Lipton and Tauch, 1987; Lipton et al., 1988). However, in these previous studies on rats, these cultures did not permit the regrowth of extensive in situ-like arbors.

It is appropriate to describe the behavior of the cells that we observed as regeneration or regrowth. In order to observe the primary formation of neurites by the RGCs, it would be necessary to isolate the retinas from prenatal animals. Indeed, it is possible that such an experiment would result in expression of growth strategies other than those observed under our experimental conditions, because regeneration does not necessarily imply a reexpression of the cells' native growth program. However, the many similarities between the neurite patterns of the cultured RGCs and those that developed in situ suggest that the strategies are similar. At the ages used in our study (P7-P56), the RGCs were postmitotic (Walsh et al., 1983), had already elaborated complex dendritic arborizations (Dann et al., 1986, 1987; Maslim et al., 1986; Ramoa et al., 1987, 1988), and had innervated target tissue in the diencephalon and mesencephalon (Leventhal et al., 1988a,b). Moreover, these kitten RGCs had been exposed to visual stimuli. Thus, the various cues available from neighboring cells, matrix, and target are not necessary during the regrowth of $\mathrm{RGC}$ neurite arbors, and the expression of signals intrinsic to a single RGC is sufficient for regrowth. Although the RGCs do not interact with other cells in our cultures, they are capable of self-interactions that may contribute to the process of neurite sculpting. An individual RGC's growing neurites continuously interact with each other (see Fig. 8), exhibiting self-avoidance cvidenced by retraction of growth concs and the repositioning of neurite segments.

Another potential set of environmental cues is the culture media. For RGCs in our culture system, the presence of glutamine and elevated levels of potassium was required to support 
the growth of the ganglion cells for more than 3-4 d in culture. Although elevated potassium levels did not necessarily induce repetitive electrical activity in cultured cells, experimental evidence indicates that chronically elevated levels of potassium (and the probable chronic depolarization of the cells) in culture media can increase the survival of neurons and, in some cases, seem to promote a variety of phenotypic changes in the cells (Scott and Fisher, 1970; Scott, 1971, 1977; Walicke et al., 1977; Chalazonitis and Fishbach, 1980; Bennett and White, 1981).

\section{Growth strategy}

The substrates used (poly-L-lysine, Cell-Tak) might be expected to allow the neurites to establish more convoluted paths than if they were growing on a less adhesive surface. This was not the case. The segments were not convoluted, and for any particular cell the fractal dimensions of the segments clustered around 1 (see Fig. 12). This result could be due to minimal binding of the growing neurites to substrate, which would tend to generate the straight segments as a result of tension developed between attachment points. The time-lapse data (e.g., Fig. 9) indicate that the growing neurites attach to the substrate only at localized points separated by distances greater than 4-6 $\mu \mathrm{m}$. This phenomenon has been reported for neurons in culture (Bray, $1979,1984)$ and is consistent with the frequent observation of rapidly retracting neurites for cells in culture longer than $72 \mathrm{hr}$ and the low average fractal dimension for the segments of most of the cells (see Fig. 12D). The occurrence of rapidly retracting neurites is common (Shaw and Bray, 1977; George et al., 1988) and is probably due to mechanical tension generated by the neurite between the points of attachment to the substratum (Bray, 1979, 1984).

The straightness measure or fractal dimension, $D$, of an individual segment gives a measure of the eventual straightness of a given inter-branch-point neurite segment; that is, it measures how straight a segment ends up being independent of the detailed history of the establishment of the segment's path. This measure does not give information about the growth path of the segment and is not a measure of straightness that is independent of the rest of the developing neuritic pattern. Instead, our use of $D$ for individual neurite segments is a measure of the eventual straightness of a segment under a multitude of influences. Thus, the average fractal dimension for a particular cell gives an overall indication of the straightness of the many neurite segments produced by that cell. For the representative cell in Figure $12 C$, the values of $D$ cluster between 1.0 and 1.1. This clustering indicates that (on average) the neurite segments of this cell approximate straight lines.

The lack of self-crossings is most likely due to an interplay of contact inhibition of neurite growth and/or the induction of branching as two neurites come into proximity and the filopodia-bearing portions of their growth cones come into contact (Kapfhammer et al., 1986; Kapfhammer and Raper, 1987a,b; Patterson, 1988; Ivins and Pittman, 1989). It is possible that contact of two growth cones causes one or both of them to lift from the substrate, and this event is capable of inducing branching or retraction of the neurite (Wessells and Nuttall, 1978). Assuming some average acute value for the initial branch angle, this contact-induced branching in combination with the contact inhibition would produce a developing neuritic pattern that would tend to fill in the available space within the limits of the intrinsic rigidity of the neurite.

The RGCs follow a growth strategy that results in the uniform coverage of a restricted territory independent of the amount or number of neurites expressed. This is illustrated diagrammatically in Figure 14. This behavior is consistent with the participation of the RGCs in the formation of the planar dendritic sheets that cover the retina and suggests a mechanism whereby distinct functional types of ganglion cells independently cover the retina and hence visual space (Wassle et al., 1981a-c).

Our data showing uniform coverage of a region independent of the number or amount of inter-branch-point segments suggest how independent uniform coverage of the entire retina could be achieved by separate functional classes of RGCs. Suppose the self-avoidance demonstrated by the cultured RGCs is taken as evidence for class-specific avoidance among the different classes of RGCs (Wassle et al., 1981c). Recent evidence on specific avoidance of neurites makes this assumption plausible (Kapfhammer et al., 1986; Kapfhammer and Raper, 1987a,b; Patterson, 1988; Ivins and Pittman, 1989). Because a given functional type of RGC provides uniform coverage of a restricted territory and demonstrates avoidance of dendrites within its own class, this conjunction of properties would result in the independent coverage of the entire retina by the various classes of RGCs (Wassle et al., 1981a-c; Perry and Linden, 1982; Perry and Maffei, 1988).

From an evolutionary perspective, this ability to independently cover visual space using local rules of dendritic growth and interaction allows for the acquisition of independent functional types of ganglion cells without significant changes in the kinds or functions of the existing types. The critical and necessary property is the ability of the RGCs to cover uniformly a restricted region through a mechanism of self-avoidance (Montague and Friedlander, 1989). If the initial dendritic outgrowth is appropriately timed, then these properties remove the burden of precisely positioning the cell bodies prior to dendritic outgrowth such that the dendrites will uniformly cover a given region of the retina. All that is required is class-specific labels (Wassle et al., 1981c) in concert with the uniform coverage property (Fig. 11). The exact territory of any specific RGC will be determined by a number of epigenetic influences, including initial cell density, afferent connections, and postsynaptic contacts.

The combination of uniform coverage of a territory along with dendritic avoidance within a class also allows each class to keep its dendritic coverage of visual space "in register" with the afferent input. Thus, in regions with low cell density, the coverage of territory will stay in register and be qualitatively the same as regions of high cell density, though the amount of afferent space covered by each cell in the low-density region will be greater than in high-density regions such as the fovea (Kirby and Chalupa, 1986). For a particular cell class, maintaining the expression of dendrites in register with afferent input highlights the ability of RGC dendrites to segregate anatomical input. In regions where the initial cell density for a particular cell class is high, each cell will individually provide relatively uniform coverage of a territory, but the territories will be smaller and the density of dendrites higher because of the higher initial cell density. In these regions, the high dendritic density, together with distinct territories established by a cell class, provides a means to separate (in register) the synaptic contacts made by afferent axons whose absolute separation in three dimensions is small.

In the cat retina, ganglion cells receive input almost exclusively on their dendrites, with few or no synapses occurring on 
the very proximal dendrites or soma (Kolb, 1979; Stevens et al., 1980). Also, the majority of these bipolar synapses on ganglion cells are diffusely distributed in the dendritic arbor, and no clear pattern to their spatial distribution has yet emerged (Sterling, 1983; McGuire et al., 1986). Hence, the growth strategy for neurite pattern formation uncovered in our cell culture system suggests the manner by which the various functional subclasses of ganglion cells provide independent and parallel sampling of visual space.

\section{The use of the Hausdorff dimension as a space-filling or coverage metric}

The analysis of the spatial structure of any neuritic pattern must account for the potentially sensitive dependence of spatial measurements on the spatial resolution of the measuring system. For example, it is easy to visualize the effect of spatial resolution on a straightforward measurement such as the total length of all the neurites of a particular cell. Because of the highly branched nature of these neurite patterns and the range of segment lengths present, the total length of all the neurites increases as the spatial resolution of the measuring system increases. As the level of the detail resolved by the system increases, the finer and shorter branches become resolvable, and these smaller elements will thus contribute to the total neurite length. Thus, the measurement of the total neurite length is not a constant, but is a function of the spatial resolution of the measuring system. The dramatic effect of spatial resolution on the stereological estimation of surface area and volume in a biological structure has been previously demonstrated (Paumgartner and Weibel, 1981).

One solution to this problem of the dependence of spatial measurements on the resolution of the measuring system is simply to choose a particular resolution or scale with which to analyze the patterns, but there is often no good a priori criterion for choosing a particular scale of measurement. Moreover, biological structures often present more complicating spatial features: they are often bushy, spiraled, convoluted, and so on. The translation of these adjectives into concise and quantifiable expressions is a major problem in a wide range of biological disciplines and is clearly a central problem in the description and understanding of neuronal morphology.

As used in this paper, the Hausdorff dimension is a scaleindependent metric and overcomes the problems of scaling described above. The term "scale-independent" is used in the following sense: Two patterns with equal values of $H$ may demonstrate very different neuritic diameters; thus, $H$ is not sensitive to the absolute scale of the neuritic pattern, but only reports the contribution of branching and segment straightness to the space-filling capacity of the pattern. For example, if a particular pattern simply was an enlarged (scaled-up) version of another pattern, then $H$ would yield the same measure for the two patterns. It is important to note that the calculation of $H$ is also valid for three-dimensional structural data and can be used as a measure of how well dendritic or axonal arbors cover a particular bounded volume. The Hausdorff dimension also could be used to assess how well a particular volume was covered by a distribution of synapses. Thus, using $H$ as a metric of coverage for a volume or an area overcomes a number of problems associatcd with analyzing highly branched or diffuse structures.

From a biological perspective, two major problems are solved by using highly branched (neuronal) structures to form functional linkages: (1) Because neurites are extremely thin, the

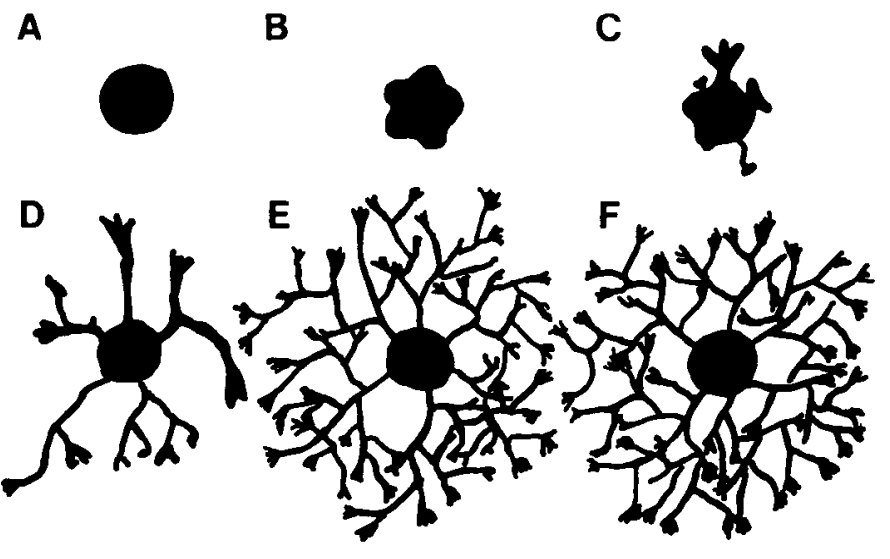

Figure 14. Illustration of the growth strategy of isolated kitten RGCs grown in cell culture. After attachment $(A)$, the membrane begins ruffling $(B)$, followed by process extension $(C$ and $D)$, and the dynamic phase of neurite remodeling by strategic repositioning ( $E$ and $F$ ). Note that while the individual details of the neuritic structure change from $E$ to $F$, the relative coverage of space and, thus, the Hausdorff dimension have stabilized.

branching allows a cell to cover a volume without occupying a significant proportion of the volume. This is true for axons and dendrites; however, long-projecting axons allow a cell to cover a volume that is not in the immediate locale of the cell. (2) Many different neurons can cover a particular volume of space, thus increasing the variety and multiplicity of synaptic contacts and interactions. The Hausdorff dimension provides insight into the contributions of single cells to a given bounded region of space and the contribution of a region of space to the functional properties of a single cell that contributes branches to that region.

\section{Appendix}

Box-counting method for estimating the Hausdorf dimension of the neurite patterns

The basic method employed for approximating the Hausdorff dimension has been reported previously (Montague and Friedlander, 1989). The mathematical estimation of the Hausdorff dimension of a set lying in $R^{n}$ and the relationship of this estimate to the box-counting method can be found elsewhere (Mandelbrot, 1982; Falconer, 1986). Neither the empirical estimation of the Hausdorff dimension nor its use in analyzing neurite patterns require detailed considerations of the mathematical subtleties associated with the definitions.

The procedure used for the estimation of the Hausdorff dimension, $H$, of the neurite patterns is illustrated in Figure $2 D-$ $G$ and in Montague and Friedlander (1989). The set of line segments, $E$, representing the neurite pattern is covered with a grid composed of square boxes of side length $d$, and the number of boxes, $k(d)$, intersected by the set $E$ was counted. By repeating this procedure over a range of values for $d$, the relationship between $k(d)$ and $d$ can be established. The estimate of the Hausdorff dimension, $s$, is obtained from the slope of the regression line for $\log (k(d))$ versus $\log (\mathrm{d})$.

The negative value of this slope $(s)$ gives and estimate of the Hausdorff dimension because the quantity $k(d) \cdot d^{s}$ is used as an estimate for the Hausdorff $s$-dimensional measure of $E$ (Falconer, 1986). If we have a reasonable estimate of $k(d)$ across a range of values of $d$, then $k(d) \cdot d^{s}$ can be used to find an upperbound estimate of the Hausdorff dimension of $E$ (Falconer, 1986). In order to obtain this estimate of the Hausdorff dimen- 
sion of $E$, we seek the least value of $s$ such that $k(d) \cdot d^{s}=0$. For neurite patterns recorded with phase-contrast optics, clearly there are empirical limitations on the estimate of $k(d) \cdot d^{s}$, and the phrase " $k(d) \cdot d^{s}=0$ " has to be translated as $k(d) \cdot d^{s}=T$ for some small $T$ and some reasonable range for $d$. To find $s$, we scek $s$ that satisfics $k(d) \cdot d^{s}=T$. To solve for $s$,

$$
\log (k(d))=-s \cdot \log (d)+\log (T) .
$$

The above expression shows that simple changes in the scale of the neurite pattern will not change this estimate of $H$, because $s$ is obtained as an asymptotic slope and changes in scale simply will shift the regression line left or right and will not change the slope of the line. This estimate of the Hausdorff dimension for the sets representing the neuritic patterns yields a value varying between 1 and 2. For a neurite pattern similar to those discussed in the text, this estimate gives a measure of how well the pattern covers a bounded region of space.

\section{Calculation of straightness measure}

In addition to calculating the space-filling capacity of neuritic patterns, the straightness of the paths taken by individual neurite segments can be determined. This is accomplished by calculating the fractal dimension of individual neuritic segments. The method of calculation has been used by Katz and George (1985) to classify and compare curves in $R^{2}$ composed of connected line segments. Their method provides a measure of the straightness (or lack of straightness) of individual growth paths. The paths could be any curve of finite length composed of or approximated by connected line segments. The measure of straightness is an estimate of the fractal dimension of the growth path. Here, the term "fractal dimension" means a number between 1.0 and 2.0 that characterizes the space-filling nature of the growth path. A value of 1.0 indicates a straight path, while values approaching 2.0 indicate increasing tortuosity. The fractal dimension is obtained by measuring the relationship between an estimate of the total length of the growth path and some measure of the linear scale of the growth path according to the expression

$$
(L)^{1 / D} \propto r
$$

or

$$
L=C \cdot r^{D}
$$

where $L$ is the total length of growth path, $r$ is the measure of linear scale of growth path, $D$ is the fractal dimension of growth path, and $C$ is a constant. The linear scale of a path should be some measure of the linear extent of the expected area that the curve tends to fill. Clearly, other information (or assumptions) about the path is required in order to estimate the shape and potential size of this area. Because Katz and George (1985) wanted to classify paths along a continuum from straight to random, they required a measure of scale and choice of eventual path geometry that would satisfactorily estimate the linear extent of both extremes of the growth path under investigation, that is, a straight line and an ideal random walk path (finite number of steps). Thus, they assumed that the random walk path tends to fill in a circular area (Barber and Ninham, 1970), and so they chose a circular geometry as the shape of the potential area filled by the path. Clearly, an estimate of the diameter of a circular area is a good measure of the linear extent of the area, so Katz and George (1985) used the diameter of the smallest circle that just encloses a particular path as the measure of the linear scale of the path. The method of calculating the Hausdorff dimension of the neuritic patterns agrees with the Katz and George straightness measure when applied to individual neuritic segments, but their method of calculation was much simpler to execute in the case of a single growth path (segment, in this casc).

\section{References}

Amthor F (1984) Morphology of on-off direction selective ganglion cells in the rabbit retina. Brain Res 298:187-190.

Armson PF, Bennett MR, Raju TR (1987) Retinal ganglion cell survival and neurite regeneration requirements: the change from Müller cell dependence to superior colliculi dependence during development. Brain Res 429:207-216.

Banker G (1980) Trophic interactions between astroglial cells and hippocampal neurons in culture. Science 209:809-810.

Banker GA, Cowan WM (1977) Rat hippocampal neurons in dispersed cell culture. Brain Res 126:397-425.

Banker GA, Cowan WM (1979) Further observations on hippocampal neurons in dispersed cell culture. J Comp Neurol 187:469-494.

Banker GA, Waxman AB (1987) Hippocampal neurons generate natural shapes in cell culture. In: Intrinsic determinants of neuronal form and function (Lasek RJ, Black MM, eds), pp 61-82. New York: Liss.

Barber MN, Ninham BW (1970) Random and restricted walks, pp 65-69. New York: Gordon and Breach.

Bennett MR, White W (1981) The survival and development of cholinergic neurons in potassium-enriched media. Brain Res 173:549553.

Bray D (1979) Mechanical tension produced by nerve cells in tissue culture. J Cell Sci 37:391-410.

Bray D (1984) Axonal growth in response to experimentally applied mechanical tension. Dev Biol 101:379-389.

Chalazonitis A, Fishbach GD (1980) Elevated potassium induces morphological differentiation of dorsal root ganglion neurones in dissociated cell culture. Dev Biol 78:173-183.

Collins F (1978) Axon initiation by ciliary neurons in culture. Dev Biol 65:50-57.

Dann JF, Buhl EH, Peichl L (1986) Development of kitten retinal ganglion cells: a morphological and quantitative analysis. Neurosci Lett [Suppl] 26:426.

Dann JF, Buhl EH, Peichl L (1987) Dendritic maturation in cat retinal ganglion cells: a Lucifer yellow study. Neurosci Lett 80:21-26.

Dann JF, Buhl EH, Peichl L (1988) Postnatal dendritic maturation of alpha and beta ganglion cells in the cat retina. J Neurosci 8:14851499.

Dotti GD, Sullivan CA, Banker GA (1988) The establishment of polarity by hippocampal neurons in culture. J Neurosci 8:1454-1468.

Dowling J (1987) The retina. Cambridge, MA: Belknap.

Eysel UT, Peichl L, Wassle H (1985) Dendritic plasticity in the early postnatal feline retina: quantitative characteristics and sensitive period. J Comp Neurol 242:134-145.

Falconer KJ (1986) The geometry of fractal sets. Cambridge: Cambridge UP.

Fukuda Y, Hsaio CF, Watanabe M, Ito H (1984) Morphological correlates of physiologically identified $Y-, X-$, and $W$-cells in the cat retina. J Neurophysiol 52:999-1013.

George EB, Schneider BF, Lasek RJ, Katz MJ (1988) Axonal shortening and the mechanisms of axonal motility. Cell Motil Cytoskel 9 48-59.

Hitchcock PF (1989) Exclusionary dendritic interactions in the retina of the goldfish. Development 106:589-598.

Ivins JK, Pittman RN (1989) Growth cone-growth cone interactions in cultures of rat sympathetic neurons. Dev Biol 135:147-157.

Johns PR, Rusoff AC, Dubin MW (1979) Postnatal neurogenesis in the kitten retina. J Comp Neurol 187:545-556.

Kapfhammer JP, Raper JA (1987a) Collapse of growth cone structure on contact with specific neurites in culture. J Neurosci 7:201-212.

Kapfhammer JP, Raper JA (1987b) Interactions between growth cones and neurites growing from different neural tissues in culture. J Neurosci $7: 1595-1600$.

Kapfhammer JP, Grunewald BE, Raper JA (1986) The selective inhibition of growth cone extension by specific neurites in culture. $J$ Neurosci 6:2527-2534. 
Katz LC, Burkhalter A, Dreyer WJ (1984) Fluorescent latex microspheres as retrograde neuronal markers for in vivo and in vitro studies of visual cortex. Nature 310:498-500.

Katz MJ, George EB (1985) Fractals and the analysis of growth paths. Bull Math Biol 47:273-286.

Kirby MA, Chalupa LM (1986) Retinal crowding alters the morphology of alpha ganglion cells. J Comp Neurol 251:532-541.

Kolb H (1979) The inner plexiform layer in the retina of the cat: electron microscopic observations. J Neurocytol 8:295-329.

Leifer D, Lipton SA, Barnstable CJ, Maslim RH (1984) The trophic support of retinal ganglion cells. Science 224:303-305.

Leventhal AG, Schall JD, Ault SJ, Provis JM, Vitek DJ (1988a) Classspecific cell depth shapes the distribution and pattern of central projection of cat retinal ganglion cells. J Neurosci 8:2011-2027.

Leventhal AG, Schall JD, Ault SJ (1988b) Extrinsic determinants of retinal ganglion cell structure in the cat. J Neurosci 8:2028-2038.

Levin EG, Lostukoff DJ (1980) Serum mediated suppression of cell associated plasminogen activator activity in cultured endothelial cells. Cell 22:701-707.

Linden R, Perry VH (1982) Ganglion cell death within the developing retina: a regulatory role for retinal dendrites. Neuroscience 7:28132837.

Lipton SA (1986) Blockade of electrical activity promotes the death of mammalian retinal ganglion cells in culture. Proc Natl Acad Sci USA 83:9774-9778.

Lipton SA, Tauch DL (1987) Voltage-dependent conductances of solitary ganglion cells dissociated from the rat retina. J Physiol (Lond) 385:361-365.

Lipton SA, Frosch MP, Phillips MD, Tauck DL, Aizman E (1988) Nicotinic antagonists enhance process outgrowth by rat retinal ganglion cells in culture. Science 239:1293-1296.

Mandelbrot BB (1982) The fractal geometry of nature. San Francisco: Freeman.

Maslim J, Webster M, Stone J (1986) Stages in the structural differentiation of retinal ganglion cells. J Comp Neurol 254:382-402.

McCarthy KO, deVellis J (1980) Preparation of separate astroglial and oligodendroglial cell cultures from rat cerebral tissue. J Cell Biol 85: 890-902.

McGuire BA, Stevens JK, Sterling P (1986) Microcircuitry of beat cells in the cat retina. J Neurosci 6:907-918.

Montague PR, Friedlander MJ (1989) Expression of an intrinsic growth strategy by a mammalian central nervous system neuron. Proc Natl Acad Sci USA 86:7223-7227.

Nelson R, Famiglietti EV, Kolb H (1978) Intracellular staining reveals different levels of stratification of on- and off-center ganglion cells in cat retina. J Neurophysiol 41:472-483.

Patterson PH (1988) On the importance of being inhibited or saying no to growth cones. Neuron 1:263-267.

Paumgartner D, Losa G, Weibel ER (1981) Resolution effect on the stereological estimation of surface and volume and its interpretation in terms of fractal dimensions. J Microsc 121:51-63.

Peichl L, Wassle H (1983) The structural correlate of the receptive field centre of alpha ganglion cells in the cat retina. J Physiol (Lond) 341:309-324.

Peichl L, Wassle H (1984) Morphological identification of on- and off-centre brisk transient ( $\mathrm{Y}^{-}$) cells in the cat retina. Proc R Soc Lond [Biol] 212:139-156.

Perry VH (1984) The development of ganglion cell mosaics. In: Development of visual pathways in mammals (Stone J, Dreher B, Rapaport DK, eds), pp 59-73. New York: Liss.

Perry VH, Linden R (1982) Evidence for dendritic competition in the developing retina. Nature 297:683-685.

Perry VH, Maffei L (1988) Dendritic competition: competition for what? Dev Brain Res 41:185-208.

Raju TR, Bennett MR (1986) Retinal ganglion cell survival requirements: a major but transient dependence on Müller glia during development. Brain Res 383:165-176.
Ramoa AS, Campbell GA, Shatz CJ (1987) Transient morphological features of fetal ganglion cells. Science 237:522-525.

Ramoa AS, Campbell GA, Shatz CJ (1988) Dendritic growth and remodeling of cat retinal ganglion cells during fetal and postnatal development. J Neurosci 8:4239-4261.

Rodieck RW, Brening PK (1983) Retinal ganglion cells: properties, types, genera, pathways, and trans-species comparisons. Brain Behav Evol 23:121-164.

Saito H-A (1983) Morphology of physiologically identified X-, Y-, and W-type ganglion cells of the cat. J Comp Neurol 221:279-388.

Scott BS (1971) Effect of potassium on neuron survival in cultures of dissociated human nervous tissue. Exp Neurol 30:297-308.

Scott BS (1977) The effect of elevated potassium on the time course of neuron cell survival in cultures of dissociated ganglia. J Cell Physiol 91:305-316.

Scott BS, Fisher KC (1970) Potassium concentration and number of neurones in cultures of dissociated ganglia. Exp Neurol 27:16-22.

Shaw G, Bray D (1977) Movement and extension of isolated growth cones. Exp Cell Res 104:55-62.

Shiosaka S, Kiyama H, Tohyama M (1984) A simple method for the separation of retinal sublayers from the entire retina with special reference to application for cell culture. J Neurosci Meth 10:229-235.

Stanford LR (1987a) W-cells in the cat retina: correlated morphological and physiological evidence for two distinct classes. J Neurophysiol 57:218-244.

Stanford LR (1987b) X cells in the cat retina: relationships between the morphology and physiology of a class of cat retinal ganglion cells. J Neurophysiol 58:940-964.

Stanford LR, Sherman SM (1984) Structure/function relationships of retinal ganglion cells in the cat. Brain Res 297:381-386.

Sterling P (1983) Microcircuitry of the cat retina. Annu Rev Neurosci $6: 149-185$.

Stevens JK, McGuire BA, Sterling P (1980) Toward a functional architecture of the retina: serial reconstruction of adjacent ganglion cells. Science 207:317-319.

Stone J, ed (1983) Parallel processing in the visual system. In: Perspectives in vision research (Blakemore $\mathrm{C}$, series ed). New York: Plenum.

Waite JH (1983) Evidence for a repeating 3,4-dihydroxyphenylalanine and hydroxyproline containing decapeptide in the adhesive protein of the mussel, Mytilus edulis. J Biol Chem 258:2911-2915.

Waite JH, Tanzer ML (1981) Polyphenolic substance of Mytilus edulis: novel adhesive containing L-DUPA and hydroxyproline. Science 212: 1038-1040.

Walicke P, Campenot R, Patterson P (1977) Determination of transmitter function by neuronal activity. Proc Natl Acad Sci USA 74: $5767-5771$.

Walsh C, Polley FH, Hickey TL, Guillery RW (1983) Generation of cat retinal ganglion cells in relation to central pathways. Nature 302: 611-614.

Wassle H, Peichl L, Boycott BB (1981a) Morphology and topography of on- and off-alpha cells in the cat retina. Proc R Soc Lond [Biol] 212:157-175.

Wassle H, Boycott BB, Illing R-B (1981b) Morphology and mosaic of on- and off-beta cells in the cat retina and some functional considerations. Proc R Soc Lond [Biol] 212:177-195.

Wassle H, Peichl L, Boycott BB (1981c) Dendritic territories of cat retinal ganglion cells. Nature 292:344-345.

Wessells NK, Nuttall RP (1978) Normal branching, induced branching, and steering of cultured parasympathetic motor neurons. Exp Cell Res 115:111-122.

Wessells NS, Johnson S, Nuttall R (1978) Axon initiation and growth cone regeneration in cultured motor neurons. Exp Cell Res 117:335345 . 